NOTICE: this is the author's version of a work that was accepted for publication in Engineering Structures. Changes resulting from the publishing process, such as peer review, editing, corrections, structural formatting, and other quality control mechanisms may not be reflected in this document. Changes may have been made to this work since it was submitted for publication. A definitive version was subsequently published in Engineering Structures, [VOL 97, (15 August 2015)] DOI\# 10.1016/j.engstruct.2015.04.012

\title{
High cycle fatigue simulation: A new stepwise load-advancing strategy
}

\author{
L. G. Barbu*, S. Oller, X. Martinez and A. Barbat \\ International Center for Numerical Methods in Engineering (CIMNE) \\ Universidad Politécnica de Cataluña \\ C1 - Campus Nord UPC, C/ Gran Capitán S/N, 08034 Barcelona, Spain \\ e-mail: lgratiela@cimne.upc.edu; sergio.oller@upc.edu; x.martinez@upc.edu; alex.barbat@upc.edu \\ ${ }^{*}$ Corresponding author. Tel.+34934016473; E-mail: lgratiela@cimne.upc.edu
}

\begin{abstract}
A stepwise load-advancing strategy for cyclic loading will be presented in this paper that yields convergence in reasonable computational time for highly nonlinear behaviour occurring past the S-N curve. The algorithm is also effective when dealing with combinations of cyclical loads. The strategy is coupled to a continuum damage model for mechanical fatigue analysis. A brief overview of the constitutive model is also presented although it is not the main focus of this work. The capabilities of the proposed procedure are shown in two numerical examples. The model is validated by comparison to experimental results.
\end{abstract}

Key words: High cycle fatigue, Continuum damage mechanics, Load-advance strategy, Post elastic behaviour.

\section{INTRODUCTION}

Steel fatigue has been extensively studied at microstructural level with a clear emphasis on its chemical structure and on the influence that the latter has on material behaviour and its failure. When looking at the phenomenon from the microscale, it can be seen that a large amount of the material internal energy is spent in a rearrangement of its internal structure to accommodate better the cyclical load, followed by the gliding of the interatomic planes phase. Metal grains suffer plastic slip and non-linear behaviour [1], and these irreversible processes are responsible for crack initiation under cyclic loading.

Regarding the high cycle fatigue (HCF) phenomenon, it is known that the type of fracture involved at macroscale level occurs with little or no plastic deformation [2]. Therefore, HCF does not introduce macroscopic plastic strain, but it introduces porosity [3]. These are the reasons that have led to describe this failure mode by means of damage models. These can be categorized into five groups: damage curve approach, crack growth- based approach, life curve modification approach, energy based damage theories and continuum damage mechanics (CDM) approaches [4]. However, in spite of the great number of models proposed in the HCF field, there is not yet a universally accepted one.

In particular, the CDM approach is based on the original concepts of Kachanov [5], [6]for treating creep damage problems. The posterior work of Chaboche [7], [8], Chaboche and Lemaitre [9], [10], Wang [11], Wang and Lou [12], Li et al. [13] and Oller et al. [14] established the CDM framework as a valid alternative to the fracture mechanics formulations in order to asses in a unified way both crack initiation and propagation. Furthermore, they enhanced the study of fatigue problems by recognizing that the theoretical structure of continuum mechanics, such as damage, is suitable for the study of nonlinear fatigue problems and that the mechanical effect known as fatigue produces a loss of material strength as a function of the number of cycles, load amplitude, reversion index, etc.

Regarding fatigue life prediction, many different approaches have been proposed such as the early methods of stress-life approach and strain-life approach [15]. One of the most used models is based on the Palmgren-Miner linear damage law [16], [17]. However, such models do not recognize the effects of prior history of loading, or the load sequence on the subsequent life. Strain-life models, on the other hand, account for the local plasticity effects at stress concentrations regions [18]. Information is abundant in literature as there are many different crack initiation models [19], with a large number of empirical models proposed for the long crack growth prediction [20]. Despite the abundant information existent on fatigue constitutive models, no attention is given to load advancing strategies utilized in numerical simulations, where the main focus of this paper resides. 
The basis of the fatigue constitutive model used was initially developed by Oller et al. [14]. The model establishes a relationship between the residual material strength and the damage threshold evolution, controlled by the material internal variables and by a new state variable of fatigue that incorporates the influence of the cyclic load. A brief overview of the constitutive formulation for the HCF case is provided in order to clarify the material behaviour exhibited in the numerical examples. Several model assumptions are to be made. Defect concentration on the microscale occurs during the whole period of cyclic loading. This is reflected in the model in a continuous reduction of material strength, occurring even in the elastic stage. Stiffness degradation occurs only in the post critical stage, once the S$\mathrm{N}$ curve has been passed and, therefore, only in the final stage before failure. The damage parameter has a phenomenological significance indicating the irreversibility of the fatigue process.

Depending on the size of the domain chosen for the fatigue numerical simulation, computational time can vary considerably. Nowadays, running simulations at macroscale level (mechanical part, structural element) continues to be a challenge, especially if the high level of structural complexity attained at the microscale needs to be taken into account to some extent at other scales. This paper aims at offering a stepwise load-advancing strategy that allows a saving of computational time and can help push the barrier of what if possible in terms of numerical simulation one step further.

The strategy can be especially effective when dealing with HCF where material lives are in the range of $10^{6}-10^{7}$ cycies. If a single loading cycle is described by $n$ loading steps, then the number of loading steps required to complete a HCF analysis would be in the order of $10^{7} \times n$. Furthermore, if the mechanical piece has a complex geometry and a high level of discretization is required at finite element level, then at each of the $10^{7} \times n$ load steps a large number of constitutive operations need to be computed for each integration point. The above serve as a clear example of why load-advancing strategies are of the utmost importance in HCF simulations.

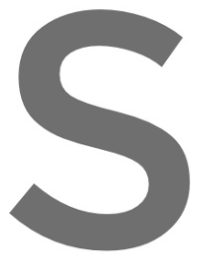

Furthermore, increasi regime from an experim properties after reaching context, this paper prov simulations beyond the limit of
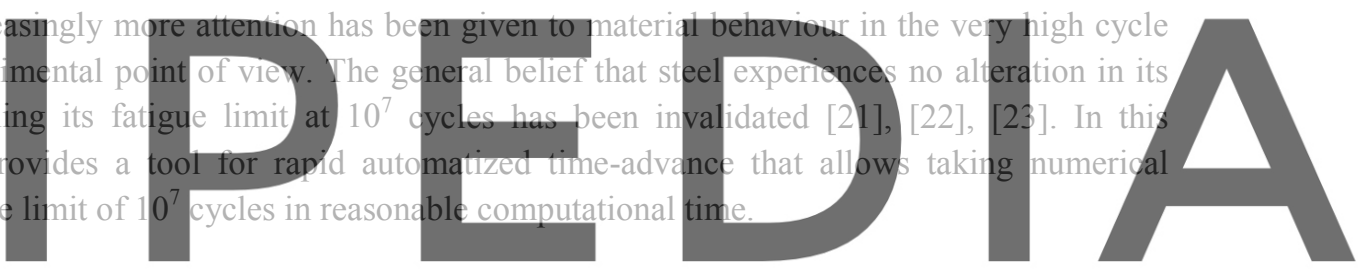

2. FATIGUE DAMAGE MODEL

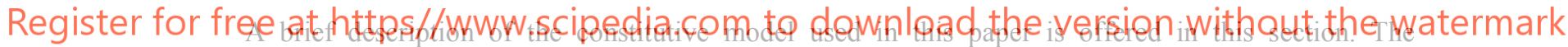
fundamentals of a fatigue continuum damage model are presented with a clear emphasis on the model's dependence on S-N curves. An exhaustive description of the formulation used can be found in Oller et al. [14], where the complete thermo-mechanical constitutive model for the prediction of fatigue effects in structures is formulated. The model is capable of taking into account the combined effect of mean stress and multi-axial stress states. The treatment of the highly complex processes generated by fatigue is made from a phenomenological point of view.

\subsection{Mechanical damage formulation}

The free Helmholtz energy is formulated in the reference configuration for elastic Green strains, $E_{i j}=E_{i j}^{e}$, as [24], [25]

$$
\Psi=\Psi\left(E_{i j}, d\right)=(1-d) \frac{1}{2 m^{0}}\left(E_{i j} C_{i j k l}^{0} E_{k l}\right)
$$

where $m^{0}$ is the material density, $E_{i j}=E_{i j}^{e}$ is the total strain tensor, $0 \leq d \leq 1$ is the internal damage variable taking values between its initial value 0 and its maximum value 1 and $C_{i j k l}^{0}$ is the original constitutive tensor.

Considering the second thermodynamic law (Clausius-Duhem inequality - [26] [27] [28]), the mechanical dissipation can be obtained as [24] 


$$
\Xi=-\frac{\partial \Psi}{\partial d} \dot{d} \geq 0
$$

The accomplishment of this dissipation condition (Equation (2) demands that the expression of the stress should be defined as (Coleman method; see [28])

$$
S_{i j}=m^{0} \frac{\partial \Psi}{\partial E_{i j}}=(1-d) C_{i j k l}^{0} E_{k l}
$$

Also, from the last expressions, the secant constitutive tensor $C_{i j k l}^{s}$ can be obtained as:

$$
C_{i j k l}^{s}(d)=\frac{\partial S_{i j}}{\partial E_{i j}}=m^{0} \frac{\partial^{2} \Psi}{\partial E_{i j} \partial E_{k l}}=(1-d) C_{i j k l}^{0}
$$

where $S_{i j}$ is the stress tensor for a single material point.

\subsection{Threshold damage function oriented to fatigue analysis. Phenomenological approach}

The effects caused by applying an increasing number of loading cycles are taken into account by means of a proposed $f_{\text {red }}\left(N, S_{\max }, R\right)$ function. This function is introduced in the above formulation in the expression of the damage threshold surface, $F^{D}\left(S_{i j}, d\right)$, proposed by [28], [29] and [30]. The number of cycles $N$ can then be incorporated as a new variable. This enables the classical constitutive damage formulation to account for fatigue phenomena by translating the accumulation of number of cycles into a

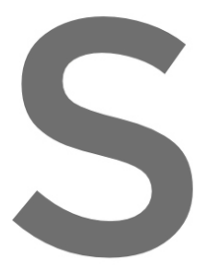
readjustment and/or mo
The non-linear beha
a fatigue state variable
maximum value of the equivalent stress, $R$
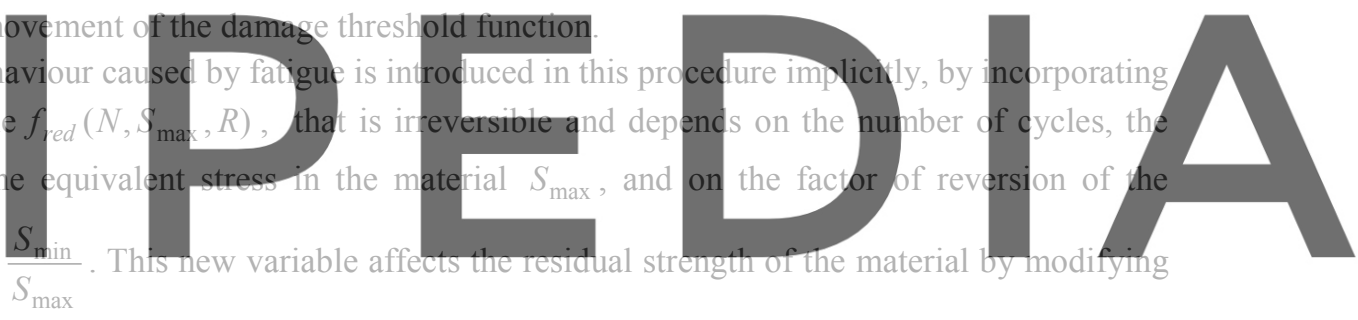

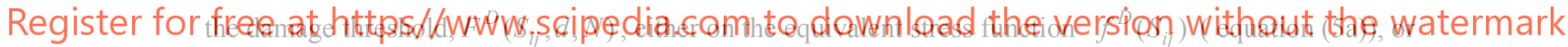
on the damage strength threshold $\bar{K}^{D}\left(S_{i j}, d\right)$ (equation (5b)) [14].

$$
\begin{gathered}
F^{D^{\prime}}\left(S_{i j}, d, N\right)=\frac{\underbrace{D}\left(S_{i j}\right)}{\underbrace{\left.f_{\max }, R\right)}_{f^{D^{\prime}\left(S_{i j}, N, R\right)}}}-\bar{K}^{D}\left(S_{i j}, d\right) \leq 0 \\
F^{D^{\prime \prime}}\left(S_{i j}, d, N\right)=f^{D}\left(S_{i j}\right)-\underbrace{\overline{K^{D}}\left(S_{i j}, d\right) \cdot f_{\text {red }}\left(N, S_{\max }, R\right)}_{K^{D^{\prime}}\left(S_{i j}, d, N\right)} \leq 0
\end{gathered}
$$

In the above, $f^{D^{\prime}}=f^{D} / f_{\text {red }}\left(N, S_{\max }, R\right)$, is the reduced equivalent stress function in the undamaged space, $K^{D^{\prime}}\left(S_{i j}, d, N\right)$ is the fatigue damage strength threshold, and $d=\int_{0}^{t} \dot{d} d t$ the damage internal variable. In the following, the form in equation (5a) has been used for the damage threshold criterion.

The evolution of the damage variable is defined as

$$
\dot{d}=\dot{\mu} \frac{\partial F^{D}}{\partial f^{D}}
$$


being $\mu$ the consistency damage factor, which is equivalent to the consistency plastic factor defined in [24]. Consequently, for the isotropic damage case,

$$
\dot{d}=\frac{\dot{\mu}}{f_{\text {red }}}
$$

\subsection{Function of residual strength reduction for fatigue - Wöhler curve definition}

Wöhler or "Stress-Num. of cycles" $(S-N)$ curves (Figure 1) are experimentally obtained by subjecting identical smooth specimens to cyclic harmonic stresses and establishing their life span measured in number of cycles. The curves depend on the level of the maximum applied stress and the ratio between the lowest and the highest stresses $\left(R=S_{\min } / S_{\max }\right)$. In Figure $1 \mathrm{~b} S_{\text {lim }}$ is the endurance limit for a reversion factor of -1 and $S_{f}^{0}$ is the material elastic limit. In Figure 1a the instantaneous stress level is depicted, while in Figure $1 \mathrm{~b}$ the cyclic stress is represented only by the maximum value it reaches in every cycle. Usually, $S-N$ curves are obtained for fully reversed stress $\left(R=S_{\min } / S_{\max }=-1\right)$ by rotating bending fatigue tests.

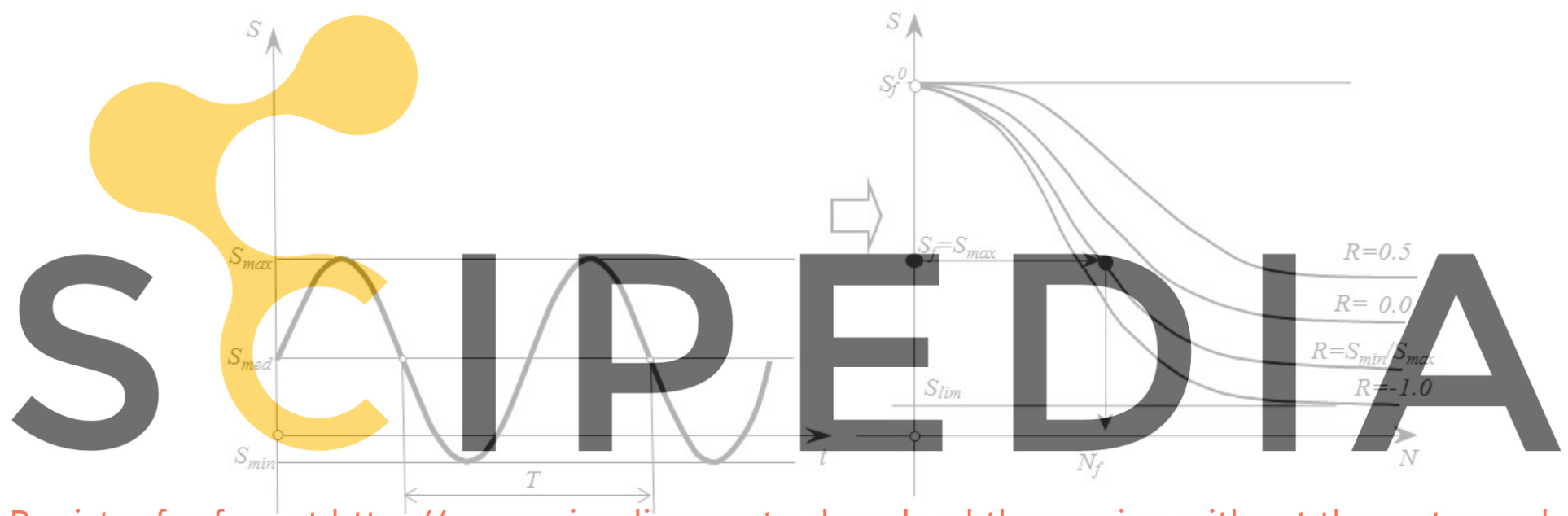

S-N curves are, therefore, fatigue life estimators for a material point with a fixed maximum stress and a given ratio $R$. If, after a number of cycles lower than the cycles to failure, the cyclic load stops, a change in the material's elastic threshold is expected due to accumulation of fatigue cycles. Furthermore, if the number of cycles exceeds $N f$, being $N f$ the fatigue life as resulting from Figure 2, the material will fail with the consequent reduction of strength and stiffness. The change in strength is quantified by the strength reduction function $f_{\text {red }}\left(N, S_{\max }, R\right)$, while the change in stiffness is taken into account by means of the damage parameter. In Figure $2 S_{e}$ is the endurance limit for any given reversion factor and $S_{t h}$ is the elastic threshold limit.

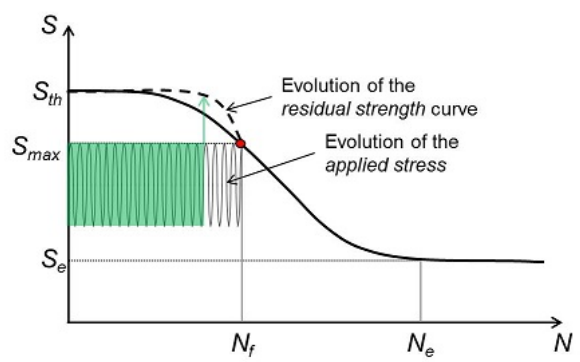

Figure 2: Schematic representation of the evolution of the residual strength with the applied load and number of cycles. 
In the case of a cyclic load with constant $S_{\max }$ and $R$ throughout the entire life of a material, the S-N curve is sufficient for determining fatigue life. However, when dealing with different load interactions the main focus resides on the residual strength curve. The curve quantifies the loss of strength in the material as the number of cycles accumulates and as load characteristics change.

All fatigue numerical simulations are based on the Wöhler curves obtained experimentally. These curves are described in an analytical form with the help of material parameters. Their expression, as well as the analytical definition of the strength reduction function, is connected to the experimental curve and, therefore, subjected to change if the material changes. Different analytical definitions can be found in [31], [32] and [33], as well as in [14].

\section{STEPWISE LOAD ADVANCING STRATEGY}

\subsection{Introduction}

The stepwise load-advancing strategy proposed in this paper uses the formulation described in Oller et al. [14] and consists of two different phases. The first one is defined by load-advance being conducted by small time increments, with the consequent load variation following a cyclic path. The second phase is characterized by load-advance being done with large increments of number of cycles.

Even though Oller et al. [14] described the possibility of advancing thru large increments of number of cycles, the process was not automatic. This implied that it could not be used in real life simulations where an in-depth tracking of the material's progressive degradation was desired, or where the loading history was comprised of several different cyclical loads.

This paper proposes an algorithm that automatically switches from one phase to the other, going repeatedly back and forth between both in accordance with the loading input and the damage increase
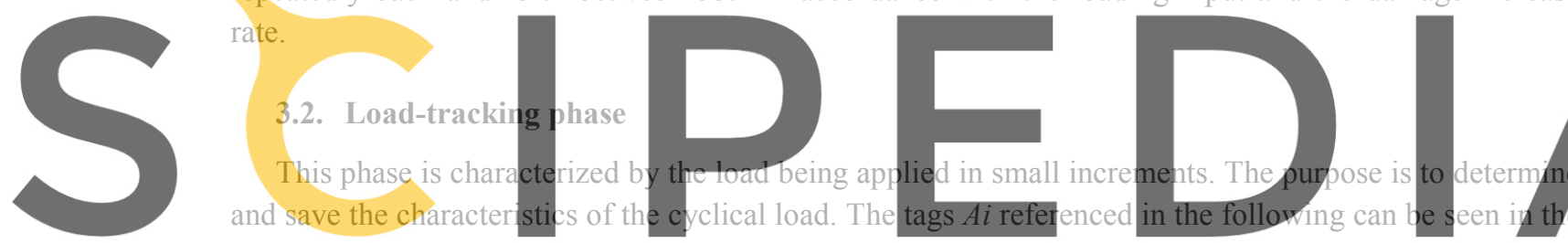

flow chart for this phase, on the left side of Figure 3.

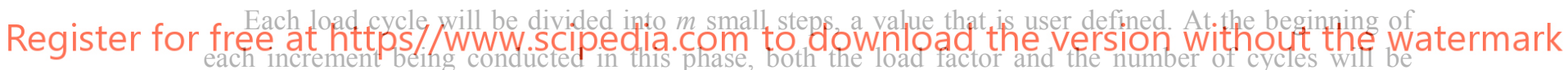

updated (A1). Based on the multiaxial stress state, the equivalent stress will be computed according to the damage criterion chosen (von Mises, Mohr-Coulomb, Tresca, Drucker-Prager). After that, the difference between the equivalent stress $f^{D}\left(S_{i j}\right)$ of current increment $k$ and previous increment $k-1$ will be compared to the difference between the equivalent stress in $k-1$ with respect to $k-2$ (A2)(See Figure 3 ). When the sign of these two quantities is different, either a maximum or a minimum has been recorded in increment $k$ - 1 (A3). After having detected both the maximum and the minimum equivalent stress for each integration point, the reversion factor is computed, $R=S_{\min } / S_{\max }$. After each new cycle $i+1$ is described, the reversion factor is compared to its value in the previous cycle $i$. The normalized variation of the reversion factor is evaluated for each integration point $G P$ and the sum of all the variations detected is computed into a stabilization norm $\eta$ as shown in equation (8) (A4).

$$
\eta=\sum_{G P}\left|\frac{R_{G P}^{i+1}-R_{G P}^{i}}{R_{G P}^{i+1}}\right| \leq \text { toler }
$$

A new value for $f_{\text {red }}\left(N, S_{\max }, R\right)$ is computed and the equivalent stress is then affected by it and compared to the damage strength threshold in the current increment (A5). The check for global convergence is made and, if this is achieved, then the stabilization norm is compared to a user defined tolerance. When this norm is below a given tolerance, it can be said that the reversion factor has a stable value throughout the solid (A6). A flag is then activated indicating that in the next increment the large 
phase algorithm should be followed. If the value of $\eta$ is not below the tolerance, several more cycles are then analysed applying small increments.

This phase is necessary at the beginning of each different cyclical load in order to determine the parameters that define the cyclic behaviour at each Gauss point of the structure $\left(R\right.$ and $\left.S_{\max }\right)$. Therefore, in case of modifying the cyclic load, a new activation is necessary.

\subsection{Large increments phase}

After the stress parameters, $R$ and $S_{\max }$, stabilize throughout the solid from one cycle to the other there is no need to keep applying small increments as there will be no change in the stress state unless either the elastic threshold is reached or the applied cyclical load changes. Therefore, the load level can be maintained at its maximum value and large number of cycles increments can be applied. The tags $B i$ referenced in the following can be seen in the flow chart for this phase, on the right side of Figure 3.

In this phase the variable is not the level of the load, kept constant at its maximum value, but the number of cycles, which, in each increment, is updated with a new large $N c$ step (B1). After obtaining the equivalent stress, a new value for $f_{\text {red }}\left(N, S_{\max }, R\right)$ is computed directly with the current number of cycles and the previously stored values for $R$ and $S_{\max }$ (B2). The equivalent stress affected by $f_{\text {red }}\left(N, S_{\max }, R\right)$ is then compared with the current damage strength threshold. If nonlinear behaviour occurs at at least one integration point a flag is activated (B3). When global convergence of the problem has been obtained in the current increment and the flag has been activated inside the constitutive loop, the next increment will be conducted with the load-tracking algorithm (B4).If convergence has been reached but the flag was not activated, in the next increment another large step will be applied.
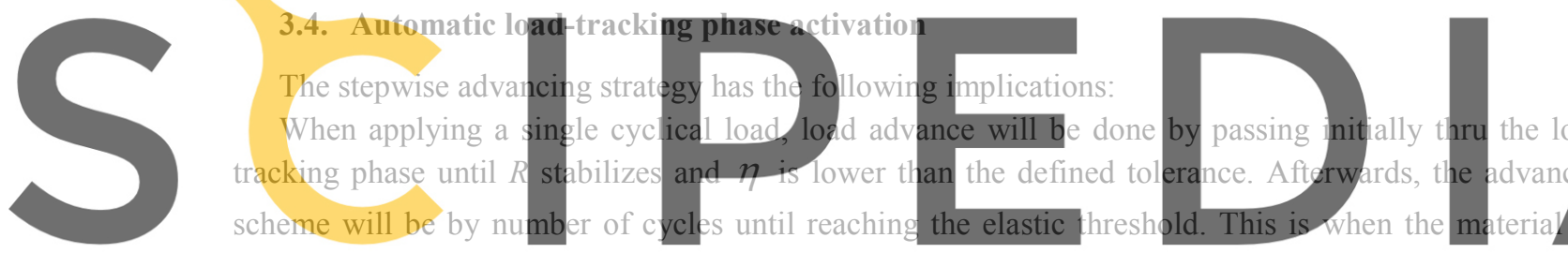

been subjected to the number of cycles indicated by the S-N curve. At this stage, the internal forces of the variation of the reversion factor and, therefore, of the stress state at integration point level. The load-

tracking phase is automatically activated. Furthermore, it will be activated at each step where damage increases $(\dot{d}>0)$ due to the change in internal forces.

The algorithm can be optimized if, after evaluating the Wöhler's $N f$ (marked dot in Figure 2) corresponding to each equivalent stress level at the beginning of the analysis, a search is made to find the minimum fatigue life throughout the solid. The resulting number of cycles can be used as the first step of the large increments phase ensuring that the entire span of number of cycles before the damage process initiates is done in one step (B1)(See Figure 3). The nonlinear processes occurring past the point damage initiates in the first Gauss point will be simulated with a user-defined $N_{c}$ step in the case of displacement controlled simulations where the material can continue bearing the cyclical load after having reached the fatigue life given by the S-N curve. This is possible due to a progressive loss of stiffness that ensures that, for the same applied cyclical displacement and having reached the S-N curve, stress in the material progressively relaxes as it suffers damage until total rupture.

In the case of applying different cyclic loads, damage can appear either due to fatigue or due to a new load being applied that leads to stress values that surpass the elastic threshold. In both cases the model will jump automatically from the large increments phase to the load-tracking phase. Even if the different cyclic loads applied induce stress levels below the elastic threshold, when passing from one cyclic load to another one of different characteristics an activation of the load-tracking is required. This is necessary regardless of the elastic regime due to the fact that, by applying a new load, the maximum equivalent stress induced and/or the reversion factor has changed and, consequently, the fatigue parameters calculated for the first load are no longer valid. 


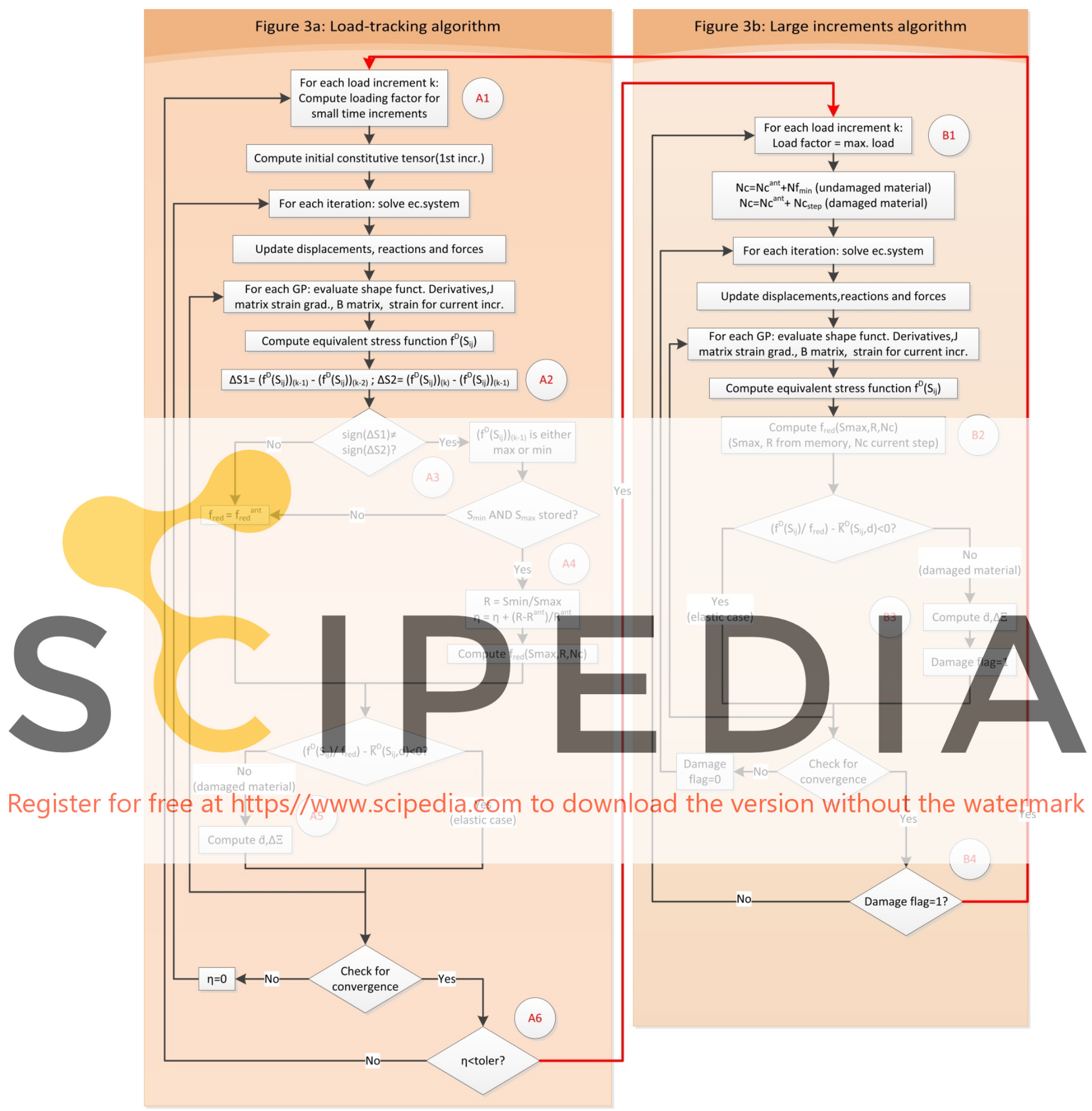

Figure 3: Flow chart for the stepwise advancing algorithm

The flow chart presented in Figure 3 shows the operations conducted in both phases, as well as the conditions required to jump from load-tracking to large increments. These jumps are indicated with hyphenated arrows.

The algorithm is user controlled by means of two parameters. The first one is the tolerance at which the reversion factor norm (defined in section 3.2.) is considered to have converged. If, for instance, a numerical tolerance of $10^{-10}$ is used, time advance runs the risk of being continually conducted in the load-tracking phase. This would lead to a dramatic increase in computational time. On the other hand, if 
the tolerance is set too high the model may no longer capture changes in the cyclical load applied, leading to an incorrect life prediction. The tolerance used for the calculation of the numerical examples presented in section 4 was $10^{-4}$ and the authors recommend this value for future use of the strategy.

The second parameter that allows the user to control the developed stepwise load advancing algorithm is the number of cycles chosen as time step for the large increments phase. The influence it has is in accordance with the level on nonlinearity of the problem. While a too low number of cycles step implies an increase in computational time, a too big one can lead to loss of solution convergence. A calibration analysis consisting of a study of the solution convergence depending on the number of cycles step is highly recommended. The analysis should begin by using large steps. Then the $N_{c}$ used as a step should be progressively lowered until convergence is reached, as this would ensure the lowest computational time.

\section{NUMERICAL EXAMPLES}

The capabilities of the stepwise load-advancing strategy, together with the fatigue constitutive model presented, will be shown with several simulations made over a hexahedral finite element subjected to cyclic loads. These examples will illustrate the fatigue behaviour under a single cyclical load and under load interaction of two different loads. After that, the model is validated comparing the results obtained from the numerical simulation with the results provided by the experiment presented in Marines et al. [34].

All the examples presented in this section have been calculated with the PLCd finite element code, where the formulation presented here has been implemented. A more detailed description of the code and some of its capabilities can be obtained from [35], [36], [37] and [38].
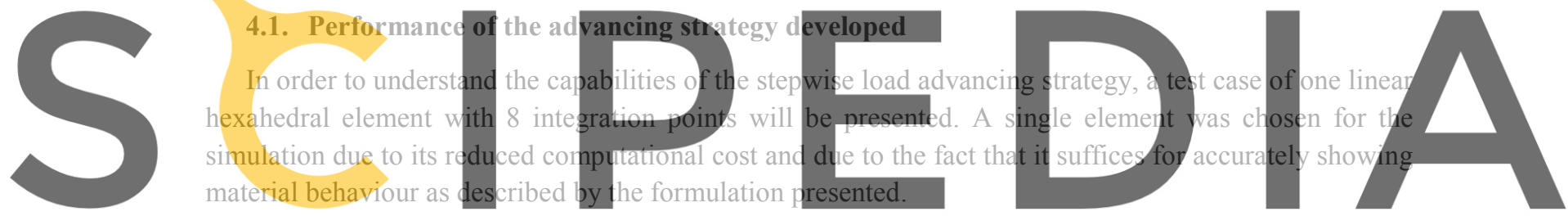

Register for free "at hetps/MWWW.Scipedia.com to download the version without the watermark

The element has one of its faces subjected to a cyclical displacement while the opposite face has boundary conditions that fix its longitudinal displacement, allowing transversal expansion and contraction.

Geometry dimensions are 10x10x10mm. The material used has the following characteristics: Young modulus $=2.01 \times 10^{5} \mathrm{MPa}$; Poisson ratio $=0.3$; Static elastic threshold is $\mathrm{S}_{\mathrm{u}}=838.9 \mathrm{MPa}$ and the material fracture energy has a value of $G_{t}=G_{c}=10 \mathrm{kN} / \mathrm{m}$. The damage model used has exponential softening and a Von Mises failure surface. The S-N curve for this material was obtained using the analytical formulation described in [32]. The parameters required in order to correctly describe the curve are $S_{u}, S_{\max }$ and $R$.

One of the model's particularities is the progressive loss of resistance leading to the initiation of damage, represented in the strength reduction curve. In order for it to be clearly differentiated from the Wöhler curve, a direct jump to the point where damage initiates was not done. Rather, an approximation of the damage initiation point was made by choosing a suitable number of cycles as the time step.

The first numerical simulation presented exhibits a load history composed of a single cyclical load, while the second simulation consists in applying two different cyclical loads.

The characteristics of the cyclical loads taken into account are: for the first one a reversion factor of 0.3 , a minimum displacement of $0.0114 \mathrm{~mm}$ and a maximum displacement of $0.038 \mathrm{~mm}$; in the second case the first load applied is the previous one and, after $10^{6}$ cycles, this load is replaced by one with a null reversion factor, a maximum displacement of $0.035 \mathrm{~mm}$ and a null minimum displacement. The number of cycles adopted as a step for the large increments phase in the first case is $10^{6}$ cycles. The second case was calculated with a step of $10^{5}$ cycles. 


\subsubsection{Single cyclical load}

Table 1 shows the stresses obtained at each integration point by the imposed displacement presented in Figure 4, as well as the fatigue life provided by the FEM model.

\begin{tabular}{|c|c|c|c|c|c|}
\hline & & \multicolumn{3}{|c|}{ (normalized with threshold limit) } & \\
\hline $\begin{array}{c}\text { Case } \\
\text { code }\end{array}$ & $\begin{array}{c}\text { Reversi } \\
\text { on factor }\end{array}$ & $\begin{array}{c}\text { Max. } \\
\text { Stress PG }\end{array}$ & $\begin{array}{c}\text { Min. } \\
\text { Stress PG }\end{array}$ & $\begin{array}{c}\text { Med. } \\
\text { Stress PG }\end{array}$ & $\begin{array}{c}\text { Nc at which } \\
\text { damage initiates }\end{array}$ \\
\hline S1 & 0,3 & 0,91 & 0,273 & 0,59 & $4,90 \mathrm{E}+06$ \\
\hline
\end{tabular}

Table 1: Characterization of the tensional state induced by the single load S1

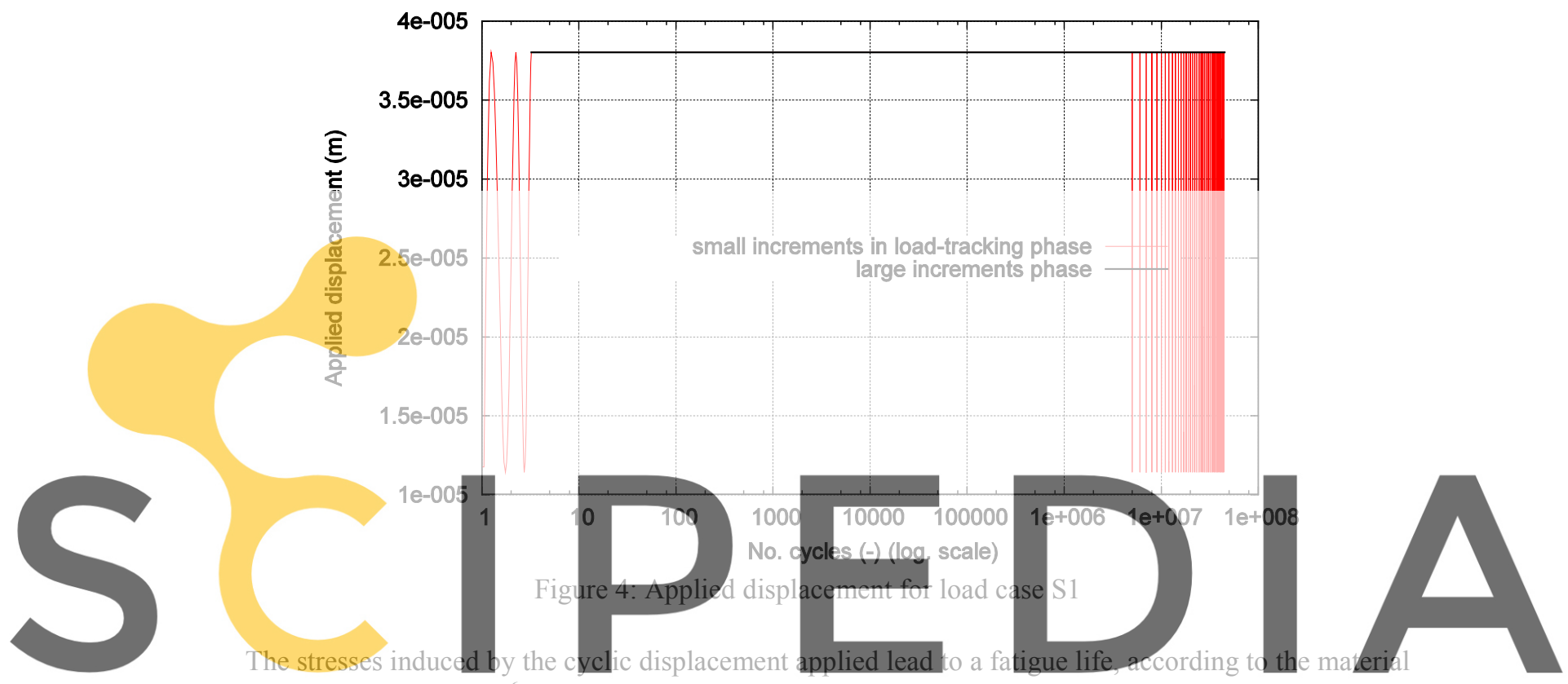

Wöhler curve, of 4,9 × $10^{6}$ cycles. This number of cycles marks the beginning of the nonlinear process

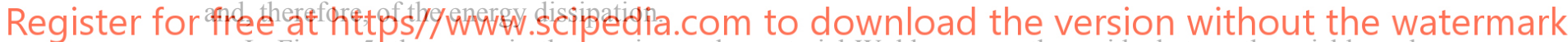

In Figure 5, the stress in the specimen, the material Wöhler curve, the residual strength variable and

the material damage value are presented. It can be seen that, while the residual strength curve is above the

Wohler fatigue life curve, there is no stress alteration or damage accumulation.

The stress level shown refers to the instantaneous stress divided by the elastic threshold. It can be seen that at the beginning an initial load-tracking stage is necessary for recording the characteristics of the stress evolution: reversion factor, maximum stress value in every cycle and stress amplitude. When the cyclic stress characteristics do not change from one loading cycle to the other (at every Gauss point) large increments start to be applied, where the load is maintained at the maximum value reached in previous cycles and only the number of cycles variable increases. At this point the material is considered to be in an elastic state but the evolution of the S-N and of the residual strength curves continues to be monitored.

Once the number of cycles applied reaches the fatigue life defined by the Wöhler curve for that level of maximum stress, event marked by the stress curve intersecting the Wöhler curve, it also intersects the residual strength curve. After this point, the stress in the material is higher than the residual strength and a softening process begins with the consequent increase of the damage variable. As soon as this event occurs at the first Gauss point a load-tracking stage is automatically activated for the entire finite element model. This is necessary as the onset of the degradation process leads to a change in the internal forces and a new equilibrium configuration is reached. When this equilibrium configuration has stabilized under small increments, the stress characteristics from one cycle to the other remain constant. This enables the application of a large increment, maintaining the load at the maximum level reached in previous stable cycles. However, when applying this large increment the equilibrium is lost as the structure is pushed further in the nonlinear zone with a consequent damage accumulation and stiffness loss. This effect can 
be seen in the stress relaxation occurring at the end of each large scale increment (Figure 5 and Figure 6).

From that point forward, after each large increment where $\dot{d}>0$, the load-tracking phase is automatically activated so that damage evolution can be monitored from cycle to cycle. If, after describing several cycles with small increments, the stress state throughout the solid has stabilized, a new large increment can be applied. This process is repeated automatically until the material reaches a state of complete degradation.
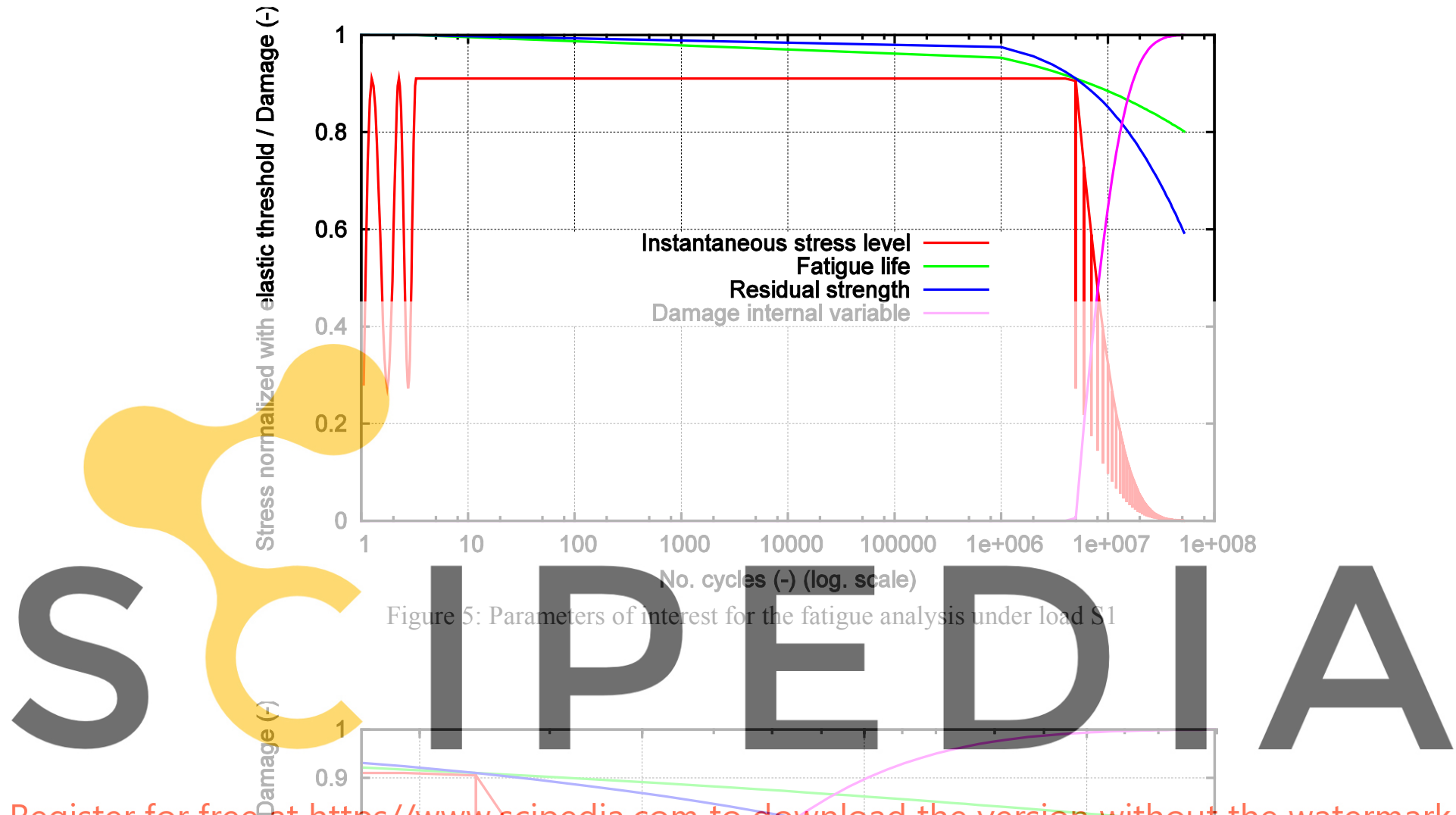

Register for free Gat latłps//www.scipedia.com to download the version without the watermark

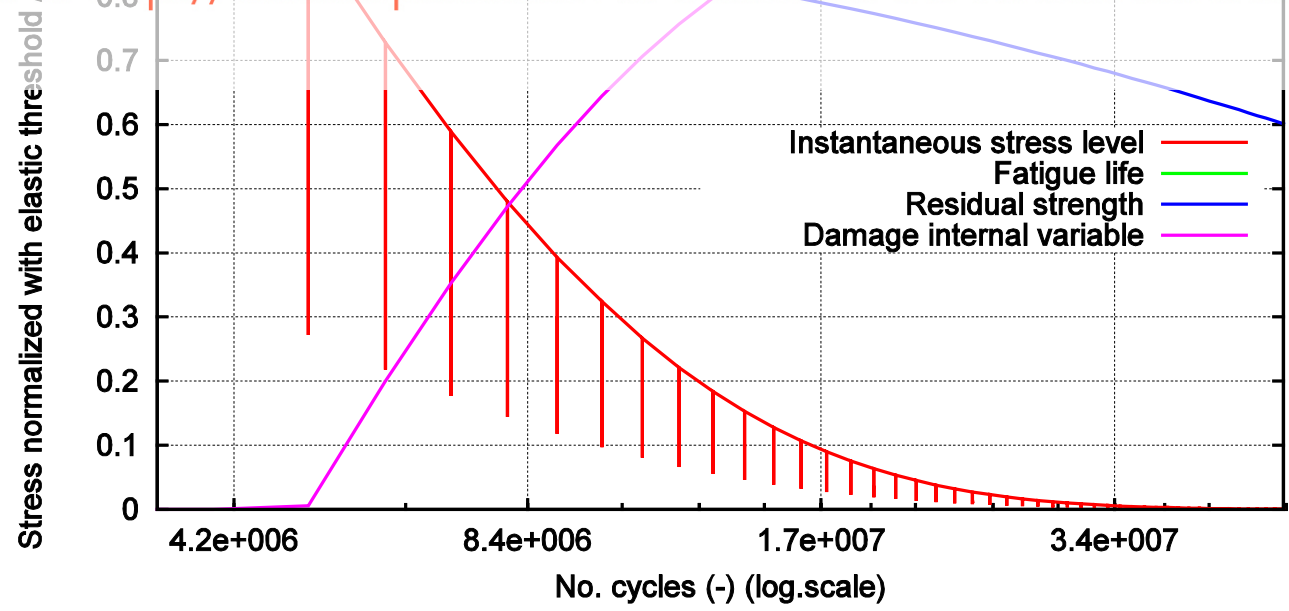

Figure 6: Parameters of interest for the fatigue analysis under load S1 in the nonlinear zone

Figure 6 zooms the end part of Figure 5 to show more clearly the material performance described. Load-tracking phase is represented by the vertical lines. Large increments phase is represented by the in between segments. Both Figure 5 and Figure 6 have a logarithmical scale along the horizontal axis.

In Figure 7, the effects of material degradation are shown in the stress-strain curve. The vertical axe refers to the instantaneous stress level divided by the material elastic limit. The large increments phase 
occurs only when the displacement is maintained at its maximum value and $\varepsilon=\varepsilon_{\max }$. Therefore, it is represented in this figure by the vertical lines descending from the point of maximum stress. The stress interval represented by each jump in the stress level quantifies the stress softening caused by a single, large number of cycles, interval. Each of these stress-softening intervals is followed by a few unloading (until minimum displacement) - loading cycles. These mark the load-tracking phase where a clear change in material stiffness is visible.

It can be seen that, as the material progressively suffers loss of stiffness, for the same large step there is less stress softening.

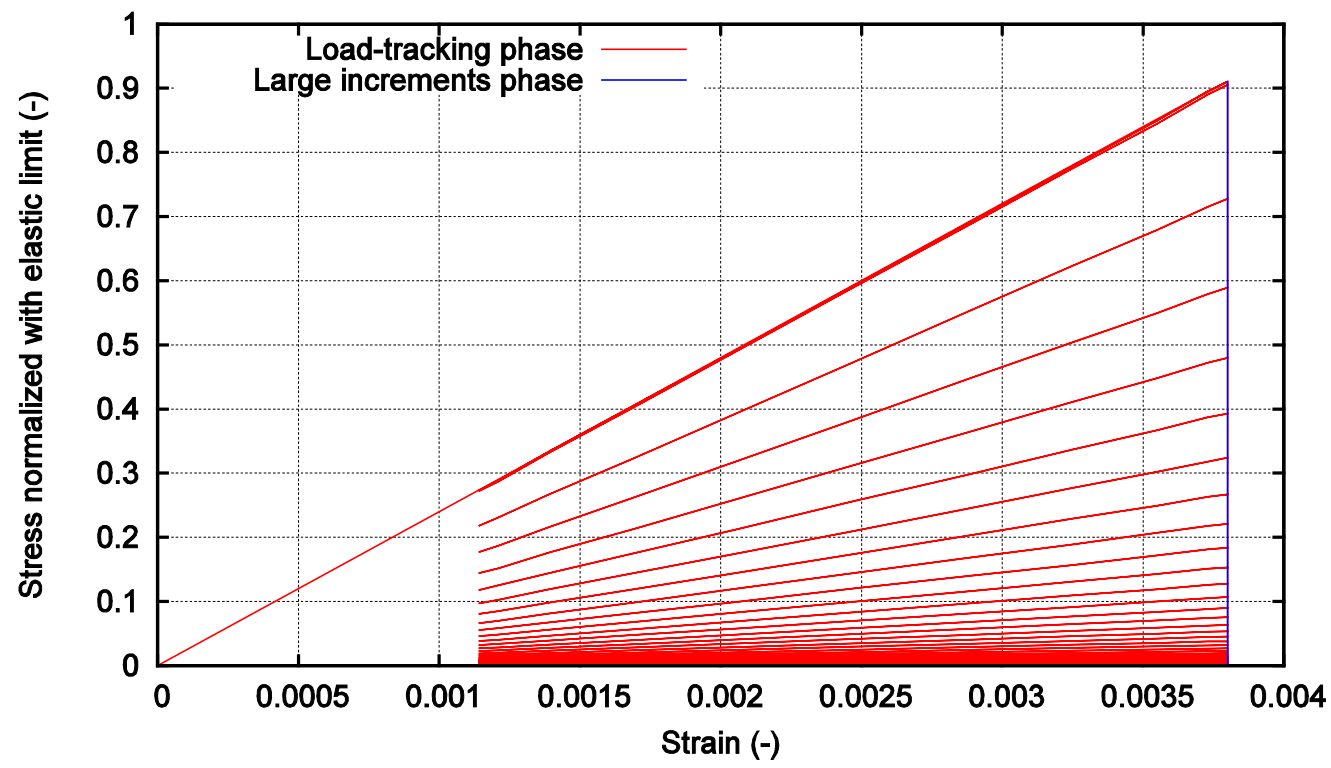

Figure 7: Stress-Strain at integration point for load S1

Furthermore, in order to demonstrate the good accuracy of the method, this simulation has been done with four different sizes for the large increments phase. Figure 8 presents the evolution of the damage internal variable as resulting from equation (6) with the number of cycles in all four cases. It can be seen that, even though the simulation is done by using different steps in the large increments phase: 50.000 , $100.000,1 \times 10^{6}$ and $5 \times 10^{6}$ cycles, the damage variable has the same evolution.

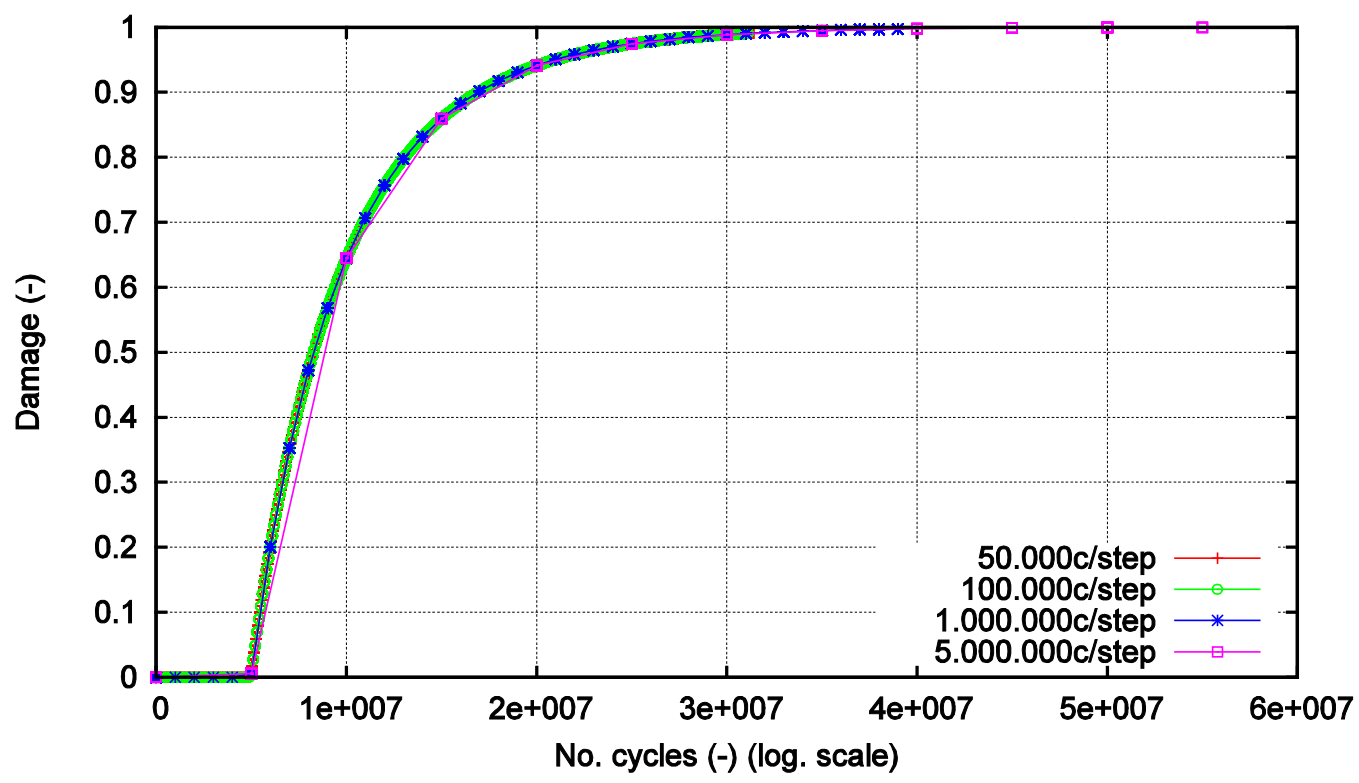

Figure 8: Evolution of the damage internal variable with the number of cycles 
As indicated in Section 3.4 the number of cycles used as a step in the large increments phase is a key parameter for the time-advancing algorithm. In Table 2 the computational time obtained for the different $N_{c}$ steps is presented. It can be seen that, even though the simulation is made on a single linear element, computational time can vary considerably depending on the number of cycles chosen as time step.

\begin{tabular}{|c|l|l|l|l|}
\hline No. of cycles considered as step & 50.000 & 100.000 & $1 \times 10^{6}$ & $5 \times 10^{6}$ \\
\hline CPU time & Oh: $8^{\prime}: 42^{\prime \prime}$ & Oh: $4^{\prime}: 8^{\prime \prime}$ & Oh: $0^{\prime}: 30^{\prime \prime}$ & Oh: $0^{\prime}: 10^{\prime \prime}$ \\
\hline
\end{tabular}

Table 2: Computational time for case S1 depending on the number of cycles chosen as step

A comparison was made between the computational time required when using the proposed loadadvancing strategy and the computational time needed if in the nonlinear stage only load-tracking were to be used. As it can be seen from Table 2, the CPU time needed in the case of a step of 1 x $10^{6}$ cycles was 30 seconds for a total analysis of $53.5 \times 10^{6}$ cycles, out of which $4.9 \times 10^{6}$ cycles consisted of elastic behaviour. When advancing only by load-tracking after the $4.9 \times 10^{6}$ elastic cycles, in 10 hours of computational time only 84.000 cycles were computed, with a correspondant damage level at the end of the 84.000 cycles of 0.018 . Taking into account this rate of advance, if the entire analysis of $53.5 \times 10^{6}$ cycles were to be conducted under load-tracking, a computational time of 265 days would be needed. This study was carried out on only one linear element. In real-life simulations, the dimensions of the problem are much larger and load history is more complex.It is of the upmost importance having a timesaving advancing strategy, and this is the topic where this paper aims at making its contribution.

\subsubsection{Load history with two different cyclical loads}

In Table 3 the stresses generated at integration point level by the imposed maximum and minimum displacements are included. These are displayed for the two cyclical loads applied, S1 and S2, as well as the fatigue life resulting from the FEM model if only one of the loads, be it S1 or S2, were to be applied until fracture. Table 3 also includes the number of cycles at which damage starts when applying both S1 and $\mathrm{S} 2$.

\begin{tabular}{|c|l|c|c|c|c|}
\hline & & \multicolumn{2}{|c|}{ (normalized with threshold limit) } & \\
\hline Case code & $\begin{array}{l}\text { Reversion } \\
\text { factor }\end{array}$ & $\begin{array}{c}\text { Max. } \\
\text { Stress PG }\end{array}$ & $\begin{array}{c}\text { Min. } \\
\text { Stress PG }\end{array}$ & $\begin{array}{c}\text { Med. } \\
\text { Stress PG }\end{array}$ & $\begin{array}{c}\text { Nc at which } \\
\text { damage initiates }\end{array}$ \\
\hline S1 & 0,3 & 0,91 & 0,273 & 0,59 & $4,90 \mathrm{E}+06$ \\
\hline S2 & 0 & 0,839 & 0 & 0,42 & $3,46 \mathrm{E}+06$ \\
\hline S1+S2 & \multicolumn{3}{|r|}{} & & $3,62 \mathrm{E}+06$ \\
\hline
\end{tabular}

Table 3: Characterization of loads S1 and S2

The simulation of the load combination was made by first imposing the S1 load during $10^{6}$ cycles, followed by load S2 being applied from $10^{6}$ cycles to $10^{8}$ cycles. By applying first load S1, followed by load S2, the resulting life for the material is $3,62 \times 10^{6}$ cycles, less than if only load S1 were applied, but more than if only S2 were applied. This shows that the formulation is capable of taking into account the effect of a cyclical load even if it is applied for a number of cycles that does not lead to failure. This is achieved by quantifying the strength reduction caused by each event in the load history and by dynamically describing the S-N curve according to changes in load characteristics.

In Figure 9 it can be seen how the slope of both curves, residual strength and S-N curve, changes as a different load starts being applied. This is possible due to the load-tracking phase being automatically activated once a change in the load is detected, as can be seen from the vertical line dividing the two stress levels exhibited. The intermediate load-tracking phase appears as a straight line due to the fact that a logarithmical scale has been used for the horizontal axis. The characteristics of the new load are consequently determined, maximum stress level and reversion factor, and with these parameters the curves readjust themselves. 


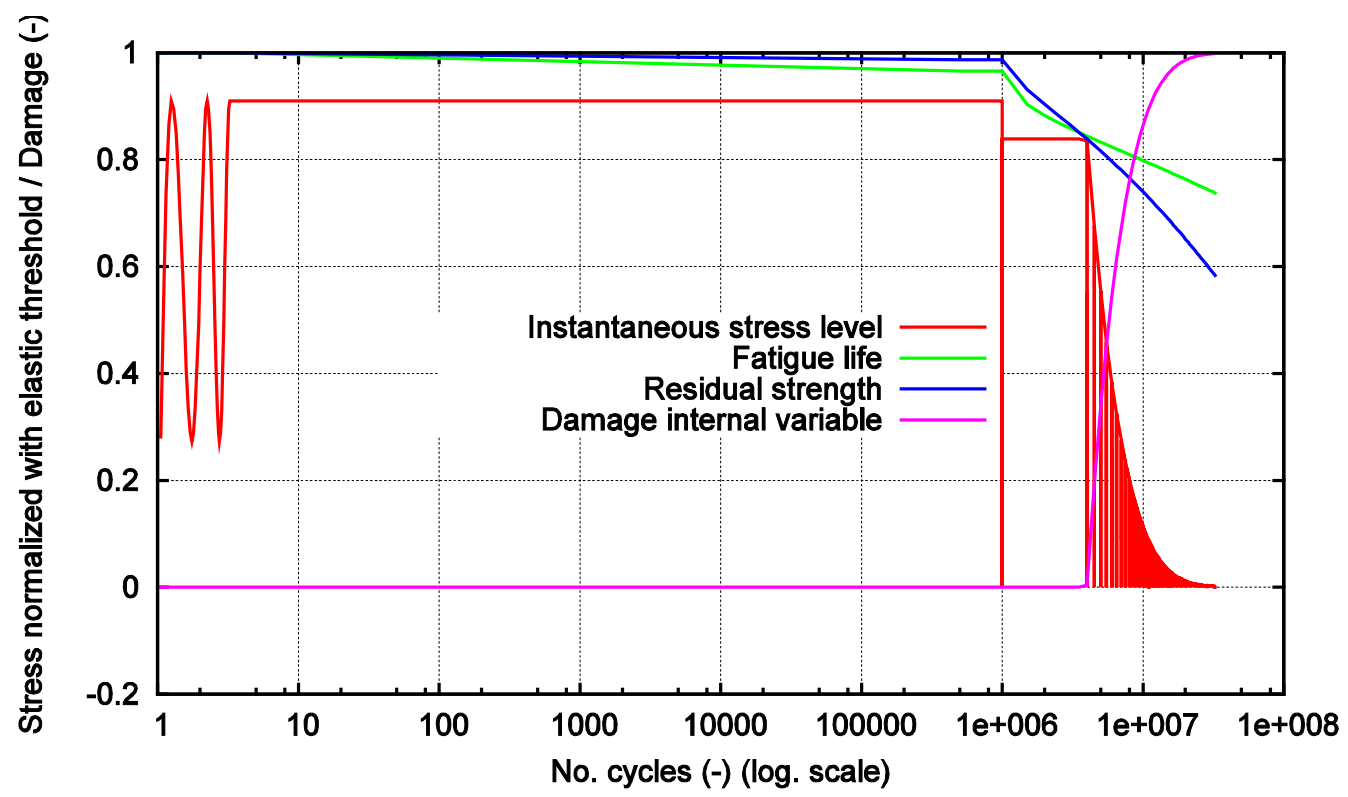

Figure 9: Parameters of interest for the fatigue analysis under loads S1+S2

Figure 10 shows the stress - strain curve where the stiffness reduction can be seen at each automatic unloading. The vertical axis refers to the instantaneous stress divided by the elastic limit. The trigger for the load-tracking stage is $\dot{d}>0$ in an increment $i$. When this happens, the load factor for increment $i+1$ will be correspondent to the load-tracking phase and unloading will have begun. Each cycle will be described by small increments until the stress state is stable again from one cycle to the other. The curve is in accordance with Figure 9, showing that the material is in the elastic state while load S1 is applied and the equivalent stress is taken to its maximum value: 0.91 of the elastic limit. Load S2 is then applied and takes the material to its fatigue life as indicated by the dynamically updated Wöhler curve. All the stiffness reduction occurs after this point. As seen in the previous case, a higher stiffness reduction can be seen in the first stages of the nonlinear process. Each one of the vertical segments depicting stress relaxation corresponds to a large increments phase that occurs only when $\varepsilon=\varepsilon_{\max }^{S 2}=0.0035$. The inclined lines mark the posterior load-tracking phase with material loading-unloading.

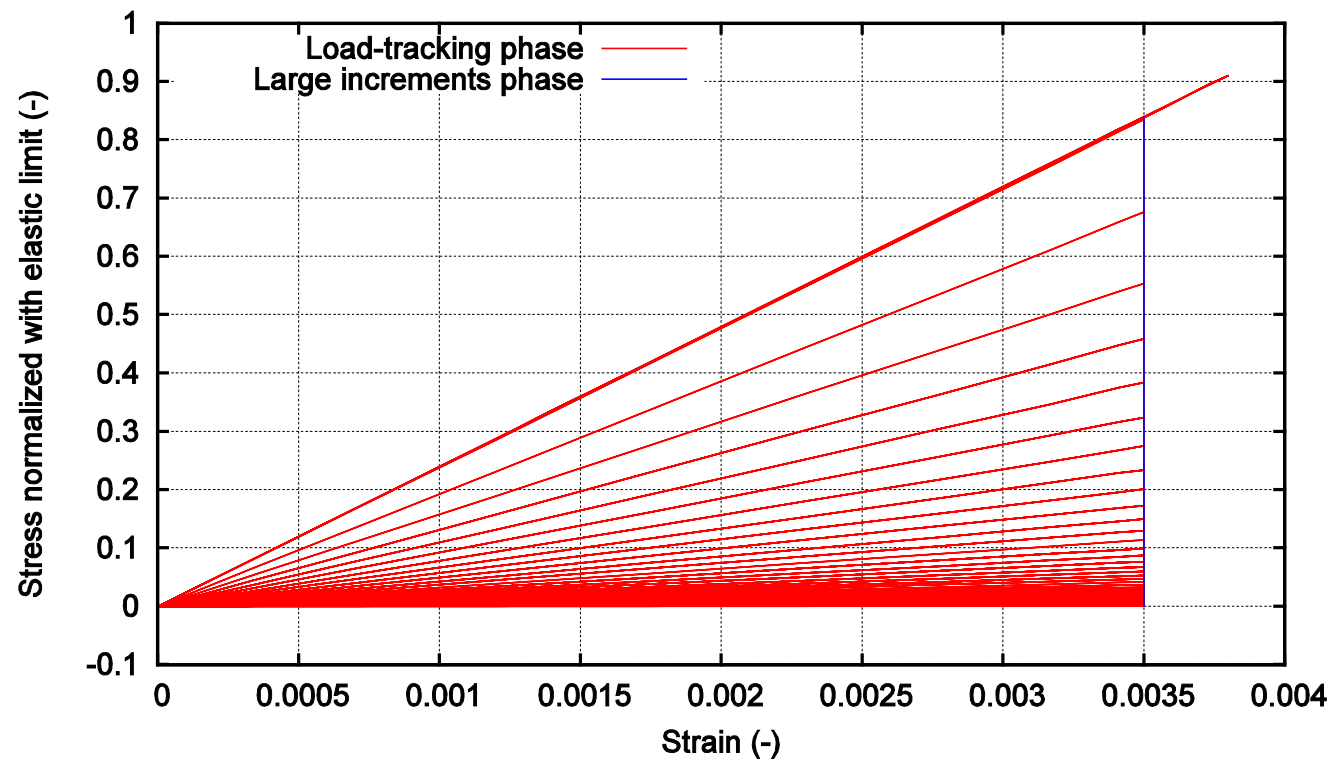

Figure 10: Stress-Strain at integration point for loads S1+S2 


\subsection{Validation of the formulation proposed}

\subsubsection{Problem definition. Geometry and material.}

The experiment undertaken by Marines et al.[34] has been chosen to validate the stepwise load advancing strategy presented in this work, together with the continuum damage model for fatigue described in section 2. In Table 4, the material characteristics given by the aforementioned authors are presented along with the shape and dimensions of the fatigue specimen adopted in the experiment. The experimental results obtained with a loading frequency of $20 \mathrm{kHz}$ and a reversion factor $\mathrm{R}=-1$ have been taken into account for the comparison with numerical results.

\begin{tabular}{|l|l|l|l|l|l|}
\hline$E_{\mathrm{d} 10 \mathrm{kHz}}$ & $E_{\mathrm{d} 20 \mathrm{kHz}}$ & $\sigma_{\mathrm{y} 0.2 \%}$ & UTS & $A$ & $\rho$ \\
$(\mathrm{GPa})$ & $(\mathrm{GPa})$ & $(\mathrm{MPa})$ & $(\mathrm{MPa})$ & $(\%)$ & $\left(\mathrm{kg} / \mathrm{m}^{3}\right)$ \\
\hline 208.3 & 211.5 & 608 & 878 & 20 & 7850 \\
\hline
\end{tabular}

Table 4: Material properties of HSLA steel, D38MSV5S

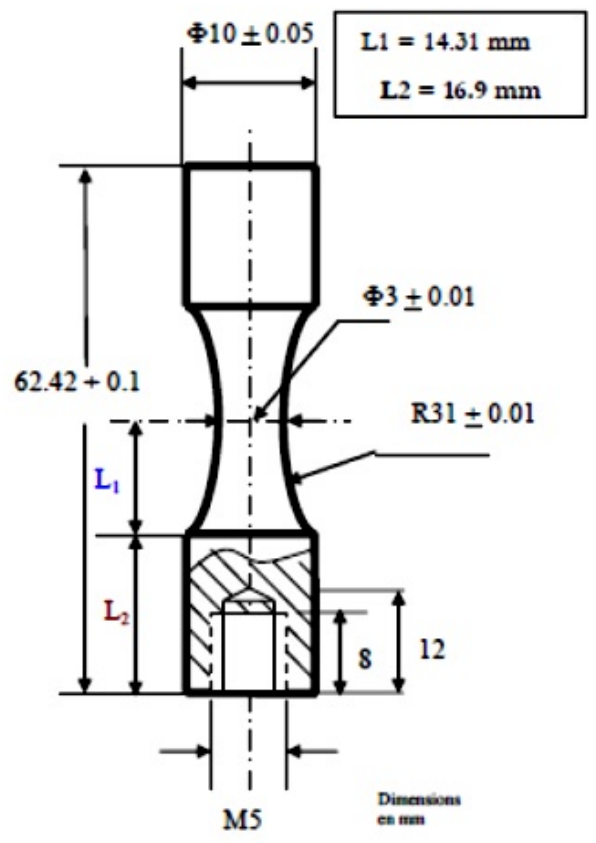

Figure 11: Shape and dimension of ultrasonic fatigue specimen as given by Marines et al.[34]

\subsubsection{Finite element model}

The fatigue specimen presented in Figure 11 has been reproduced by means of a finite element model. Due to the symmetrical nature of the geometry and loading and boundary conditions only half of the specimen has been modelled in order to minimize computational time.

The semi-cylindrical volume has been meshed with linear hexahedral elements as shown in Figure 12. The mesh has 2666 nodes and 1920 elements. Each finite element is described with eight integration points. 


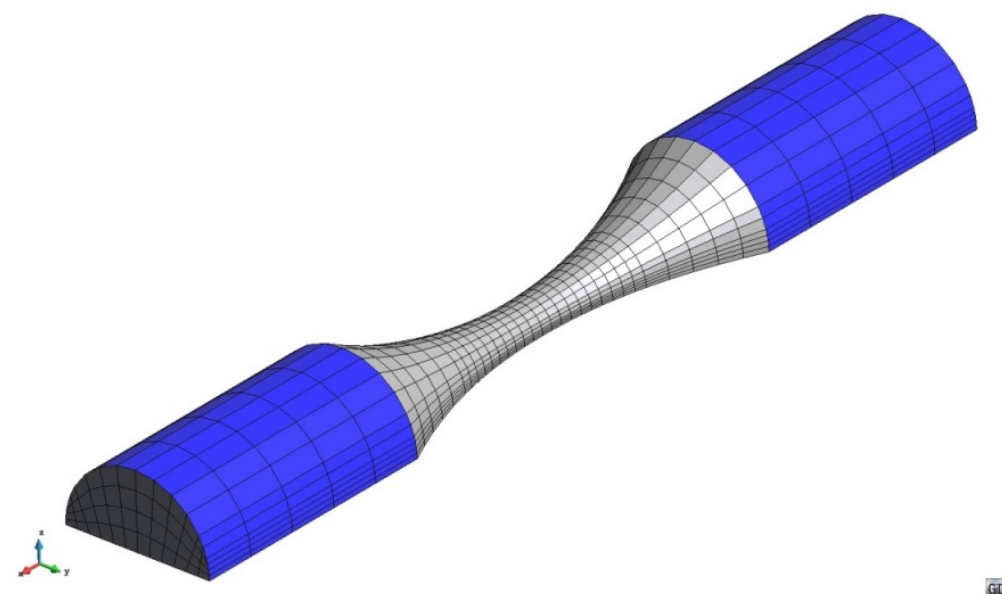

Figure 12: Finite element mesh of linear hexahedral elements

The boundary conditions applied are shown in Figure 13. The specimen is restrained at one end and subjected to a cyclical displacement at the other end. The entire base is defined with a symmetry condition.

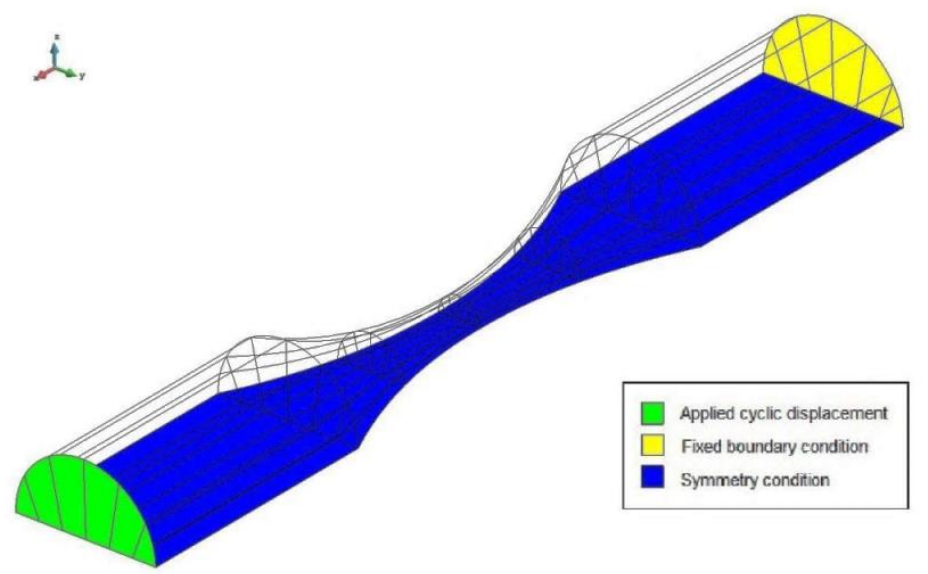

Figure 13: Boundary and loading conditions for the analysed geometry

The analytical formulation for the S-N curve used by the numerical model was the one presented in [32]. The parameters used for the adjustment of the curve to the experimental one proposed by Marines et al. [34] are $S_{u}=608 \mathrm{Mpa}, S_{\lim }=325 \mathrm{Mpa}, \alpha=\beta=1.3$; a correction factor of 1.23 was applied when calculating the auxiliary term $\mathrm{AUX}=1 / 1.26+\mathrm{R} / 3.3$.

\subsubsection{Results obtained from the experimental tests}

In Figure 14, the results obtained by Marines et al. [34] are presented. As expected, a scatter of test results can be seen both for $20 \mathrm{kHz}$ resonating material and for the $30 \mathrm{kHz}$ one. Since the material characteristics taken into account for the numerical analysis are that of the $20 \mathrm{kHz}$ one, simulations have been run only with the maximum stress levels exhibited for this particular testing frequency. The experimental results showed that, even though the geometry and loading conditions are axisymmetric, the failure mode is not symmetric [34]. 


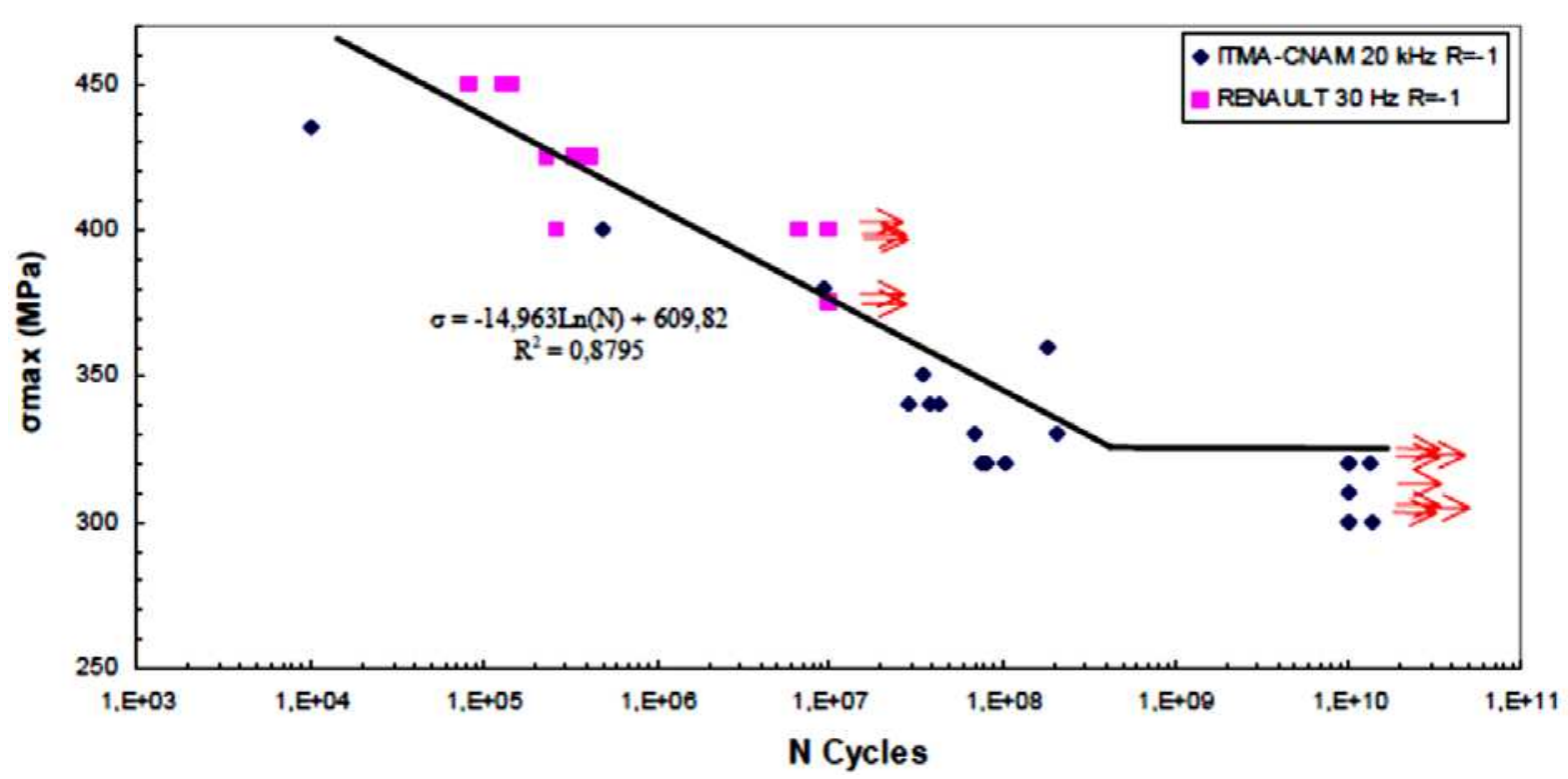

Figure 14: Fatigue S-N curve of HSLA steel D38MSV5S with $\mathrm{R}=-1,20 \mathrm{kHz}$ and 30kHz [34]

\subsubsection{Validation of the results obtained with the numerical simulation}

The expression for the S-N curve proposed in Figure 14 by Marines et al. [34] has been compared to the numerical results obtained from the described finite element model. The comparison can be seen in Figure 15. Since the model has a deterministic nature, no scatter can be seen in numerical results. The numerical data depicted in Figure 15 is in accordance with Table 5 where the information on the exact characteristics of each simulation case is given.

\begin{tabular}{|c|c|c|c|}
\hline $\begin{array}{c}\text { Case } \\
\text { code }\end{array}$ & $\begin{array}{c}\text { Reversi } \\
\text { on factor }\end{array}$ & $\begin{array}{c}\text { Max. } \\
\text { Stress GP } \\
\text { (MPa) }\end{array}$ & $\begin{array}{c}\text { Nc at which } \\
\text { damage initiates }\end{array}$ \\
\hline BA1 & -1 & 435 & $0,17 \cdot 10^{6}$ \\
\hline BA2 & -1 & 400 & $1,50 \cdot 10^{6}$ \\
\hline BA3 & -1 & 380 & $5,30 \cdot 10^{6}$ \\
\hline BA4 & -1 & 360 & $20,03 \cdot 10^{6}$ \\
\hline BA5 & -1 & 350 & $39,50 \cdot 10^{6}$ \\
\hline BA6 & -1 & 340 & $78,50 \cdot 10^{6}$ \\
\hline BA7 & -1 & 330 & $160,00 \cdot 10^{6}$ \\
\hline BA8 & -1 & 320 & $1 \mathrm{E9}$ (run-out) \\
\hline
\end{tabular}

Table 5: Fatigue life as resulting from the numerical simulation. Same stress levels and reversion factor as [34]. $(20 \mathrm{kHz})$ 


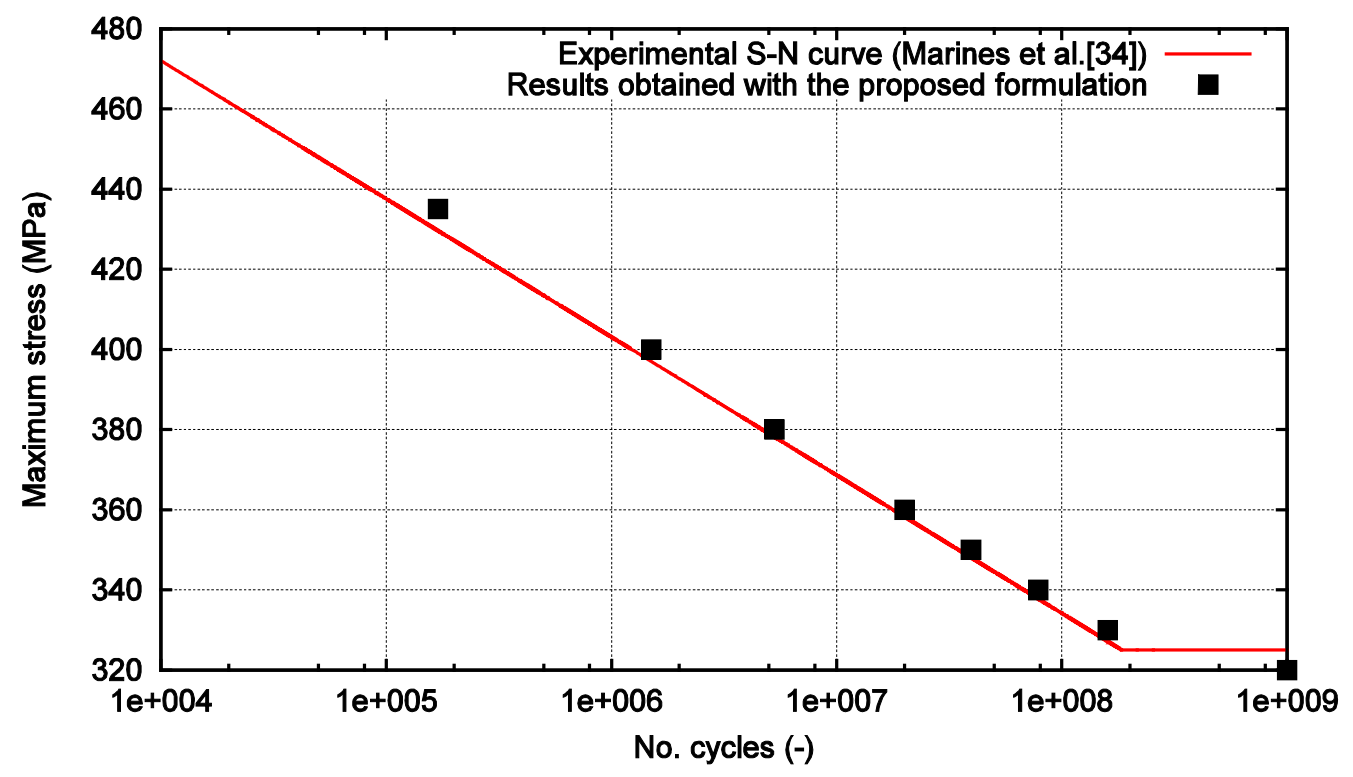

Figure 15: S-N curve for HSLA steel D38MSV5S. Experimental vs. numerical.

Some observations are to be made, however, in order to better understand the results presented in Figure 15. The points signalled as results obtained with the proposed formulation, mark the start of the stiffness reduction. In a force controlled test, when the force level is taken to the following maximum after the fatigue life depicted in Figure 15, abrupt failure occurs. However, as the numerical model has been defined with displacement controlled boundary conditions, when the next maximum displacement is reached after arriving at the fatigue life given in Table 5, a reduction of the stress level occurs and the material can continue to be cyclically loaded. If an unloading would be made at this point a stiffness reduction in proportion to the stress relaxation would be observed. For a better understanding of this effect a detailed description of the fatigue behaviour is shown in the next section for one of the cases ran for the validation.

Summarizing, the fatigue life charted in Figure 15 represents the number of cycles up until which the maximum stress induced by the applied cyclical displacement remains unaltered. Once this point is surpassed, stress relaxation occurs along with damage accumulation, stiffness reduction and a subsequent change in internal forces. If the test is force controlled, the specimen fractures abruptly. If the test is displacement controlled, the material is taken to complete fracture more progressively.

\subsubsection{Analysis of the performance of the material model. In-depth analysis of stiffness reduction at integration point}

In this section an in-depth analysis of the material's behaviour is made for a maximum induced stress level of $350 \mathrm{MPa}$. The results are similar for all the other simulations ran.

The experimental tests have shown that fracture initiates on the surface of the specimen. This is due to defects present in the microstructure that lead to void nucleation and microcrack initiation and propagation. Fracture initiation is not symmetric and, furthermore, in the last stages of the nonlinear process, due to microstructural imperfections and defects, fracture propagation leads to non-symmetrical behaviour.

In the numerical simulation, fracture initiation is not symmetrical, but a large part of the propagation process occurs under symmetry to the y-y axis. However, in the last stages, before complete rupture (third image in Figure 18), due to numerical round off the solution loses symmetry.

A monitoring of model parameters has been made at the first integration point that shows complete degradation. In Figure 16 are depicted: the evolution of the residual strength, Wöhler fatigue life, equivalent stress and damage internal variable with a logarithmical scale along the horizontal axis. It can 
be seen that the stress state suffers no alteration until it intersects the S-N curve.

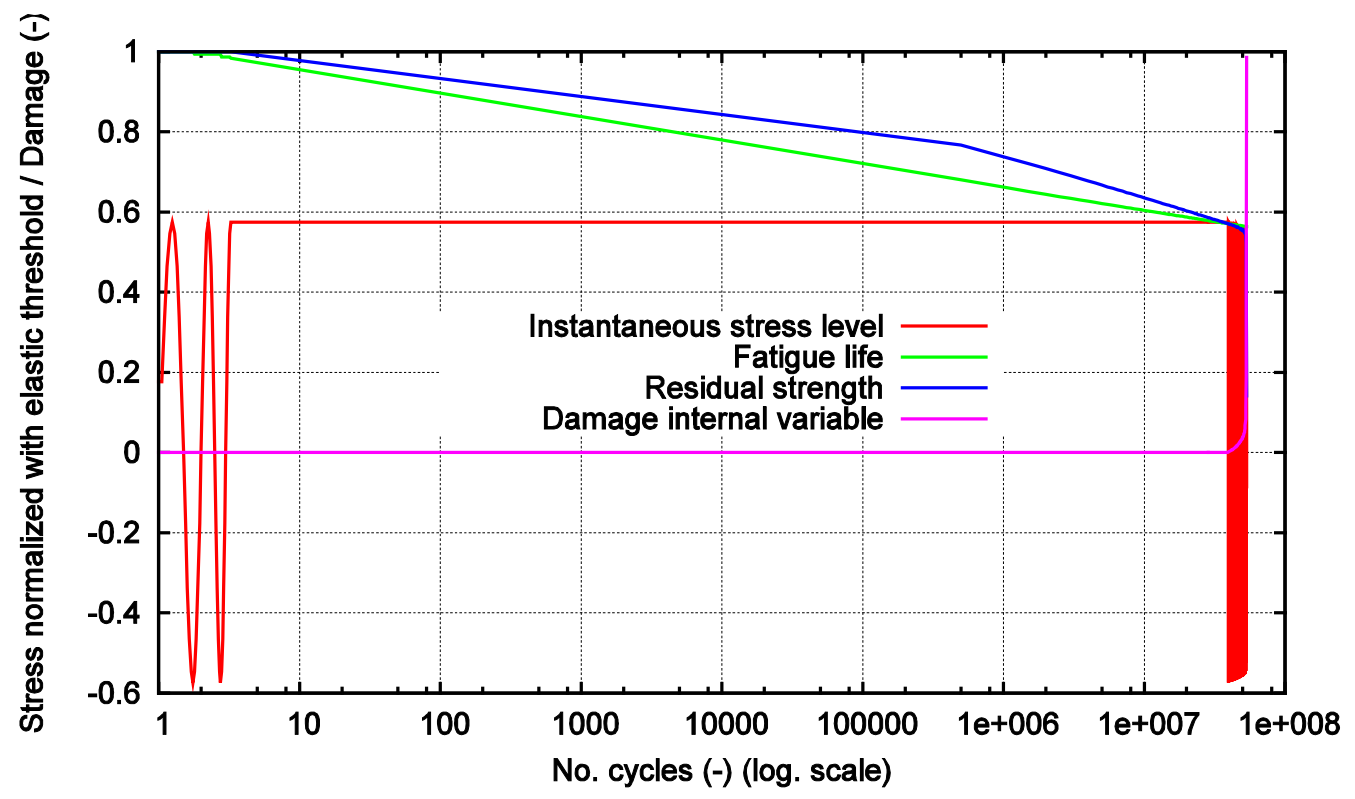

Figure 16: Parameters of interest for the fatigue analysis of D38MSV5S specimen at the first integration point that fractures completely

Figure 17 shows a zoom on the evolution of the variables in the non-linear zone (past the intersection with the S-N curve). Here the succession between the large increments phase and the load-tracking phase can be better seen. Also, it can be observed how $90 \%$ of the degradation is concentrated in the last two large steps with nearly $80 \%$ in the last one. For this case, $5 \times 10^{5}$ cycles has been adopted as step for the large increments phase. Therefore, although the specimen is subjected to approximately $5.35 \times 10^{7}$ cycles until it fractures completely, $80 \%$ of the stiffness reduction occurs in the last 500000 cycles, deeming the fracture a brittle type one.

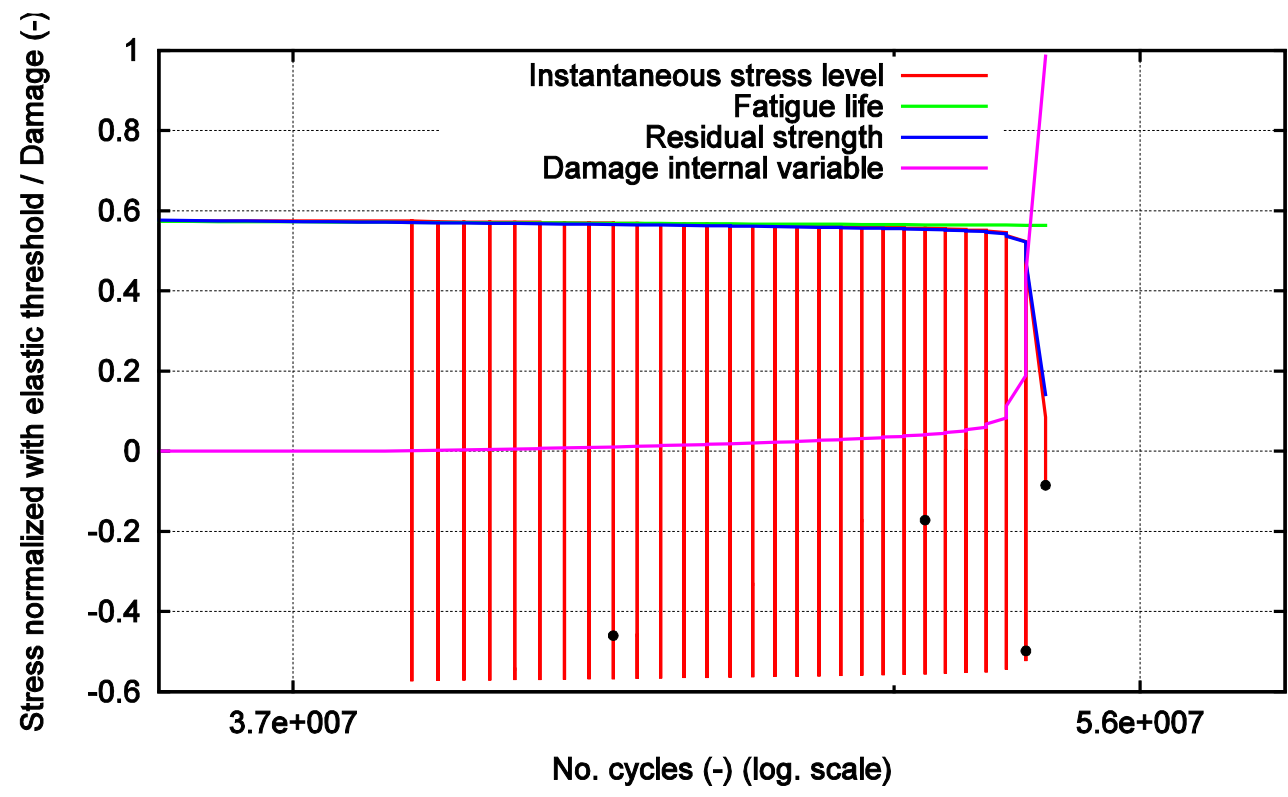

Figure 17: Zoom on fatigue parameters of interest in the nonlinear zone (post S-N curve).Dots indicate the analysis steps at which damage evolution is presented in Figure 18. 
Figure 18 shows a view of the specimen from above and a view of the cross section at different number of cycles (analysis steps). Each one of the steps represented is marked in Figure 17 chronologically with a black dot.

The images show the damage evolution in the specimen, both on surface and in depth, as the number of cycles increases. Damage initiates on the surface of the specimen in the area with the smallest crosssectional diameter, as expected, after $3.95 \times 10^{7}$ cycles. Afterwards it propagates symmetrically until approximately $5.3 \times 10^{7}$ cycles (third image in Figure 18), when it localizes in one side of the specimen. This is believed to be due to a numerical round off that directs the posterior damage accumulation to the right side of the specimen, as can be seen in Figure 18.
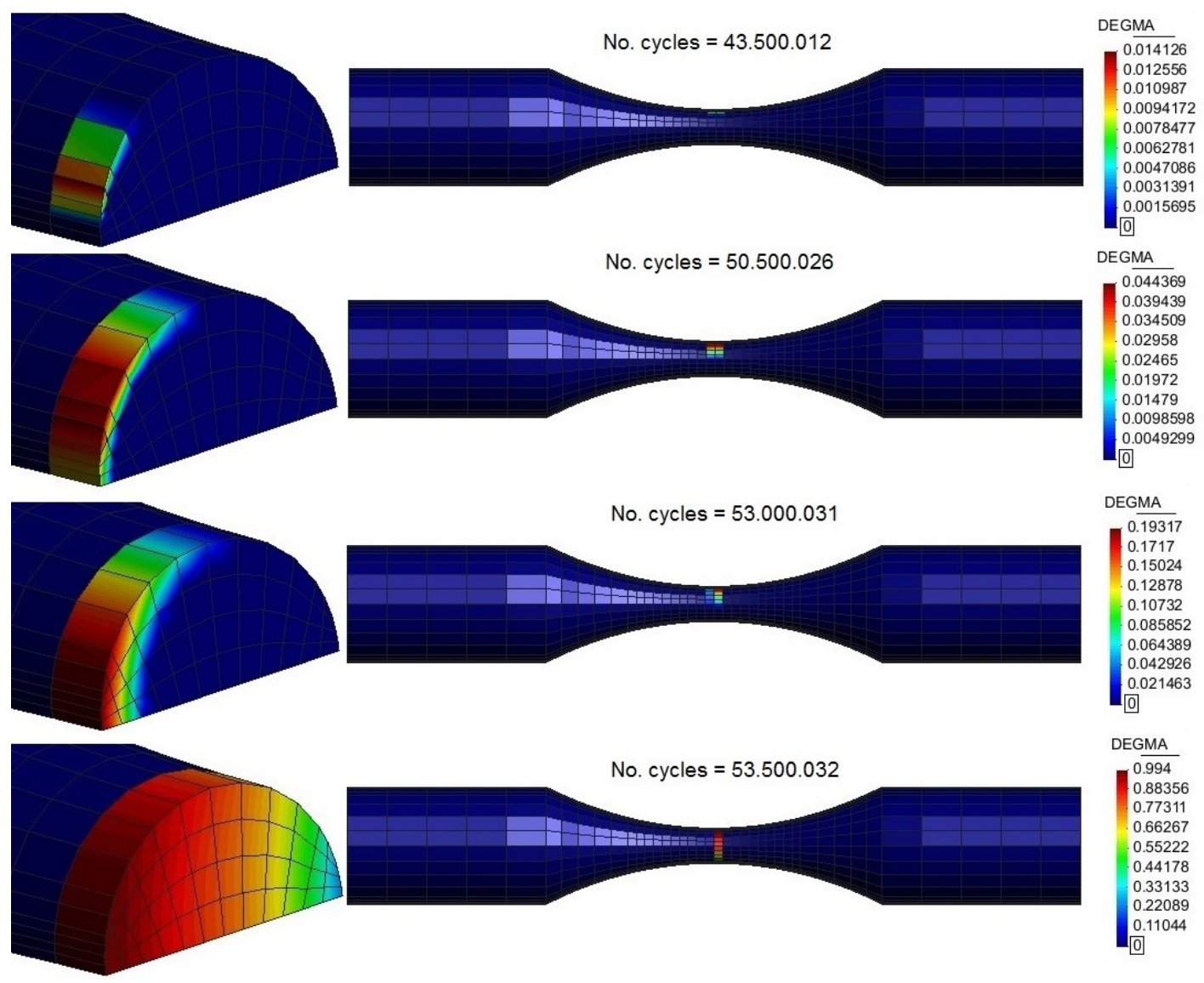

Figure 18: Damage evolution for a maximum induced stress of 350MPa and $\mathrm{R}=-1$

The upper image in Figure 19 presents the deformed shape of the specimen when the last maximum displacement before total fracture is applied. A necking can be seen in the central region although the specimen is not yet completely fractured. From that point in the analysis, the applied displacement is taken from its maximum value to its minimum one, when the specimen is subjected to compression. That eventually causes the rupture into two parts (lower image in Figure 19). 


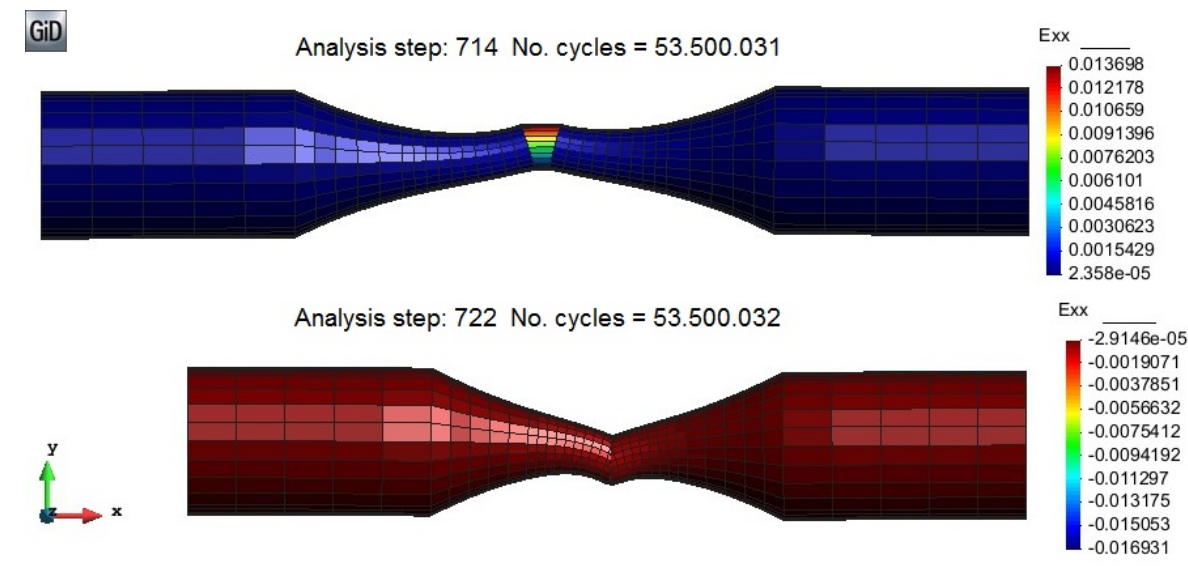

Figure 19: Deformed shape (x 200) at the last maximum stress before rupture and at the last minimum stress, when rupture occurs

\section{CONCLUSIONS}

This paper has presented a fatigue formulation that takes into account the effects caused by the accumulation of number of cycles of loading by an alteration in the strength and in the stiffness of the material. First, material strength is reduced until it reaches the induced maximum stress level. From that point on, energy dissipation is done by means of stiffness reduction.

The cyclical load is taken into consideration by means of two parameters: maximum stress generated by the applied load and stress reversion factor. Both parameters have a direct influence on the onset of damage and on the strength reduction. This allows a quantification of the effects induced by different cyclical loads and discrimination between different load-applying orders.

In order to take full advantage of this formulation a stepwise load advancing strategy has been proposed. Its aim is to save computational time and improve convergence in a number of cases, such as load combinations and nonlinear material behaviour.

The procedure divides the load in two different loading processes: load tracking and large increments phases. The jump between the two loading schemes is made automatically, depending on the mechanical response of the structure. The algorithm is user controlled by means of the stabilization tolerance and by the number of cycles considered as large step.

The capabilities of the formulation have been shown in a test case of a single cyclical load and in one with a load history comprised on two different loads. Validation of the proposed model has been done by reproducing the experimental results obtained by Marines et al. [34]. These tests show that, with the strategy proposed, it is possible to perform fatigue simulations taking into account material nonlinearities and load variations straightforward, as the advancing strategy takes care automatically of the procedure required at each step (load-tracking or large increments) in order to obtain the most accurate result with the lowest computational cost.

\section{Acknowledgements}

This work has been supported by the Research Fund for Coal and Steel through the ULCF project (RFSR-CT-2011-00029), by the European Research Council under the Advanced Grant: ERC-2012-AdG 320815 COMP-DES-MAT "Advanced tools for computational design of engineering materials", by the research collaboration agreement established between Abengoa Research and CIMNE and by the Spanish Government program FPU: AP2010-5593.

\section{REFERENCES}

[1] Kanvinde, M. and Deierlein, G.G. Cyclic void growth model to assess ductile fracture initiation in structural steels due to Ultra Low Cycle Fatigue, J Engng Mech 2007;133(6):701-12. 
[2] Barbu, L.G., Oller, S., Martínez, X. and Barbat, A.H. Stepwise advancing strategy for the simulation of fatigue problems. Proceedings of the 12th International Conference on Computational Plasticity - Fundamentals and Applications, COMPLAS 2013: 1153-64.

[3] Schijve, J. Fatigue of Structures and Materials, 2nd ed. Berlin: Springer-Verlag; 2009.

[4] Fatemi, A. and Yang, L. Cumulative fatigue damage and life prediction theories: a survey of the state of the art for homogeneous materials, Int J Fat 1998; 20:9-34.

[5] Kachanov, L. M. Time to the rupture process under creep conditions, Izv. Akad. Nauk. SSR Otd. Tech. Nauk. 1958; 8:26-31.

[6] Kachanov, L. M. Introduction to Continuum Damage Mechanics, Martinus Nijhoff, The Netherlands; 1986.

[7] Chaboche, J.L. Fracture mechanics and damage mechanics: complementarity of approaches, In Numerical Methods in Fracture Mechanics, Proceedings of the Fourth International Conference 1987: 309-24.

[8] Chaboche, J.L. A differential law for nonlinear cumulative fatigue damage, In Materials and Building Research, Annales de l'ITBTP 1974; 39:117-24.

[9] Lemaitre, J. and Chaboche J. L. Mechanics of Solid Materials , Cambridge University Press, U.K.; 1990.

[10] Lemaitre, J. and Chaboche J. L. Aspect phenomenologique de la rupture par endommagement, J Mech App 1978; 2(3):317-65.

[11] Wang, J. A continuum damage mechanics model for low-cycle fatigue failure of metals, Engng Fract Mech 1992; 41(3):437-41.

[12] Wang, T. and Lou, Z. A continuum damage model for weld heat affected zone under low-cycle fatigue loading, Engng Fract Mech 1990; 37(4): 825-9.

[13] Li, C., Qian, Z. and Li, G. The fatigue damage criterion and evolution equation containing material microparameters, Engng Fract Mech 1989; 34(2):435-43.

[14] Oller, S., Salomón, O. and Oñate, E. A continuum mechanics model for mechanical fatigue analysis, Comput Mat Sci 2005; 32:175-95.

[15] Holman, R. K. , Liaw, P. K., Methodologies for predicting fatigue life, JOM: the journal of the Minerals, Metals \& Materials Society 1997; 49(7):46-52.

[16] Palmgren, A.,Die Lebensdauer von Kugellagern (The service life of ball bearings), Zeitschrift des Vereines Deutscher lngenieure 1924; 68(14):339-41.

[17] Miner, M. Cumulative fatigue damage, J Appl Mech 1945; 12:159-64

[18] Vasudevan,A.K, Sadananda, K, Glinka, G. Critical parameters for fatigue damage Int J Fat 2001; 23(1): $39-53$

[19] Halford, G.R. Cumulative fatigue damage modeling — crack nucleation and early growth, Int J Fat 1997; 19(1):S253-60

[20] Hoeppner, D. W., Krupp, W. Prediction of component life by application of fatigue crack growth knowledge, Engng Fract Mech 1974; 6:47-70.

[21] Marines, I., Bin, X. and Bathias, C. An understanding of very high cycle fatigue of metals, Int J Fat $2003 ; 25: 1101-7$.

[22] Bathias, C. and Ni, J. Determination of fatigue limit between $10^{5}$ and $10^{9}$ cycles using an ultrasonic fatigue device, ASTM 1993; 1211:141-52.

[23] Bathias, C. There is no infinite fatigue life in metallic materials Fat Fract Eng Mat Struct 1999; 22:559-65.

[24] Lubliner, J. Plasticity Theory, Macmillan Publishing, U.S.A.; 1990.

[25] Luccioni, B., Oller, S. and Danesi, R. Coupled plastic-damage model, Comp Meth App Mech Eng 1996; 129:81-90.

[26] Malvern, L. Introduction to the Mechanics of Continuous Medium, Prentice Hall, U.S.A.; 1969.

[27] Lubliner, J. On thermodyamics foundations of non-linear solid mechanics, Int J Non-Lin Mech 1972; 7: 237-54. 
[28] Maugin, G. The Thermomechanics of Plasticity and Fracture, Cambridge University Press, U.K.; 1992.

[29] Simo, J. and Ju, J. Strain and stress based continuum damage models - I Formulation, Int J Solids Struct $1987 ; 23: 821-40$.

[30] Oliver, J., Cervera, M., Oller, S., and Lubliner, J. Isotropic damage models and smeared crack analysis of concrete, In Second international conference on computer aided analysis and design of concrete structures $1990 ; 2: 945-58$.

[31] Salomón, O., Oller, S. and Oñate, E. Fatigue Analysis of Materials and Structures Using a Continuum Damage Model, Int J Forming Processes 2002; 5: 493-503.

[32] Suero, A. and Oller, S. Tratamiento del Fenómeno de Fatiga Mediante la Mecánica de Medios Continuos, Monografía CIMNE No 45, Barcelona, Spain ;1998.

[33] Oller, S., Oñate, E., Canet, J. Miquel and Botello, S. A plastic damage constitutive model for composite materials, Int J Solids Struct 1996; 33:2501-18.

[34] Marines, I., Galván, D. and Bathias, C. Fatigue life assessment of high-strength, low alloy steel at high frequency, Arabian J Sci Eng 2008; 33(1B): 237:47.

[35] Martinez, X., Oller, S., Rastellini, F. and Barbat, A. A numerical procedure simulating RC structures reinforced with FRP using the serial/parallel mixing theory, Comp \& Struct 2008; 86(15-16):160418.

[36] Martinez, X., Oller, S., Barbu, L.G. and Barbat, A.H. Analysis of ultra low cycle fatigue problems with the Barcelona plastic damage model, Proceedings of the 12th International Conference on Computational Plasticity - Fundamentals and Applications, COMPLAS 2013; 352-63.

[37] Martinez, X., Oller, S., Barbu, L., Barbat, A. and De Jesus, A.M.P. Analysis of ultra-low cycle fatigue problems with the Barcelona plastic damage model and a new isotropic hardening law, Int. J. Fat. 2015; 73:132-42.

[38] Barbu, L.G., Oller, S., Martínez, X. and Barbat, A.H Coupled plastic damage model for low and ultra-low cycle seismic fatigue. 11th. World Congress on Computational Mechanics 2014; 2955-66, ISBN 978-84-942844-7-2. 